\title{
TIEMPO DE INTERRUPCIÓN DE NEGOCIOS EN LA CIUDAD DE MÉXICO POR DAÑOS DIRECTOS Y EFECTOS INDIRECTOS EN EDIFICIOS A CAUSA DEL SISMO DEL 19S DE 2017
}

\author{
David Ortiz Soto ${ }^{(1)}$ y Eduardo Reinoso Angulo ${ }^{(1)}$
}

\begin{abstract}
RESUMEN
Después del sismo ocurrido el 19 de septiembre de 2017 en México, una gran cantidad de negocios establecidos en la Ciudad de México dejó de operar temporalmente e incluso de forma definitiva. De acuerdo con lo observado tras este evento destructivo, en este trabajo se identifican las fuentes de interrupción del negocio: Protocolos de seguridad iniciales, Suspensión de servicios públicos de suministro, Efectos de vecindario y Daños en los componentes del edificio, y se propone un modelo para determinar el tiempo de interrupción de negocio, IN, con base en la inactividad de la edificación. Con la finalidad de tener valores de referencia para los datos de entrada, se documentan los tiempos de evaluación de edificios, restablecimiento de servicios públicos, demolición de edificios, entre otros aspectos relevantes para la CDMX. Finalmente, los conceptos se ejemplifican con un negocio formal hipotético establecido en una edificación de dos niveles de mampostería confinada y en los resultados se obtiene que habría una paralización total de las actividades empresariales por más de un mes debido a daños menores en la infraestructura de energía eléctrica y algunos daños estructurales en la planta alta. Además, se concluye que, aunque la interrupción de negocios depende de múltiples factores, la participación de los Ingenieros Estructuristas es trascendental para minimizar el tiempo de IN, especialmente en la evaluación de la seguridad de los edificios y la rehabilitación de las infraestructuras.
\end{abstract}

Palabras clave: interrupción de negocios; pérdida por sismo; tiempo inactivo del edificio; tiempo de reparación estructural

\section{BUSINESS INTERRUPTION TIME IN MEXICO CITY DUE TO DIRECT DAMAGES AND INDIRECT EFFECTS IN BUILDINGS DUE TO THE EARTHQUAKE ON SEPTEMBER 19, 2017}

\begin{abstract}
After the earthquake on September 19, 2017 in Mexico, many businesses established in Mexico City stopped operating temporarily and even definitely. According to what was observed after this destructive event, in this work the sources of business interruption are identified: Initial security
\end{abstract}

Artículo recibido el 3 de abril de 2019 y aprobado para su publicación el 30 de diciembre de 2020. Se aceptarán comentarios y/o discusiones hasta cinco meses después de su publicación.

(1) Instituto de Ingeniería, UNAM, Av. Universidad 3000, Col. Universidad Nacional Autónoma de México, 04510 Ciudad de México, e-mail: DOrtizS@iingen.unam.mx; ereinosoa@iingen.unam.mx

DOI: $10.18867 /$ ris. 104.538 
protocols, Suspension of public supply services, Neighborhood effects and Damages in the components of the building, and a model is proposed to determine the business interruption (BI) time, considering the inactivity of the building. In order to have reference values for the input data, the times of evaluation of buildings, restoration of public services, demolition of buildings, among other relevant aspects for Mexico City are documented. Finally, the concepts are exemplified with a hypothetical formal business established in a building with two levels of confined masonry and in the results it will be obtained that there would be a total stoppage of business activities for more than a month due to minor damages in the electric power infrastructure and some structural damage on the ground floor. In addition, it is concluded that, although business interruption depends on multiple factors, the participation of Structural Engineers is essential to minimize BI time, especially in the evaluation of the safety of buildings and the rehabilitation of infrastructures.

Keywords: business interruption; earthquake loss; downtime of building occupancy; structural repair time

\section{INTRODUCCIÓN}

Los sismos generan grandes pérdidas económicas tanto por los daños directos como por el cierre de los negocios. Por ello, la reanudación de las operaciones normales de los negocios lo más pronto posible es fundamental para minimizar pérdidas e inclusive evitar el fracaso de estos, así como para lograr la recuperación social y económica de las zonas afectadas (Alesch et al., 2009).

Los sismos de septiembre de 2017 en México propiciaron una paralización temporal o definitiva de muchos negocios de la Ciudad de México y de otros estados de la República debido a daños directos en los inmuebles. Quedó evidenciado que puede pasar mucho tiempo sin que se comience la rehabilitación de los edificios; por ejemplo, en Juchitán de Zaragoza, Oaxaca se pueden observar varios edificios dañados a casi 500 días después de estos eventos catastróficos, entre los que destacan la catedral principal, el palacio municipal y el mercado municipal, donde los negocios que estaban establecidos en los últimos dos inmuebles citados se vieron forzados a reubicarse en los alrededores, sin embargo, estos sufrieron notables pérdidas por la disminución de los clientes pese a la relocalización. Asimismo, se registró que diversas unidades económicas tuvieron que suspender sus actividades aun cuando sus edificios resultaron sin perjuicios directos. Por ello, es una práctica común en algunos sectores que los dueños de los negocios tengan contratado un seguro de daños directos para que la rehabilitación estructural y arquitectónica del edificio o de los contenidos sea lo más pronto posible y, además, un seguro para la pérdida por interrupción en caso de que ocurra algún evento muy fuerte.

La mayoría de los modelos que se han propuesto para estimar la pérdida económica probable por daños para diversas amenazas, principalmente para sismo, se han enfocado en el costo de reparación de la estructura (Scholl, 1979; ATC-13, 1985; Ordaz, et al., 2000; Haselton, et al., 2007 y 2011; Ramírez et al., 2012). Existen softwares que estiman la pérdida a partir del cálculo formal del riesgo sísmico de edificios e infraestructura como CAPRA (ERN, 1996) y HAZUS (FEMA, 2013), sin embargo, ambos consideran la interrupción de negocios de manera muy aproximada.

El estudio de pérdidas por interrupción de negocio es relativamente reciente. Estas pérdidas muchas veces son mayores con respecto a las pérdidas por el daño a la propiedad (Tierney, 1997), además de que son más difíciles de estimar puesto que dependen de muchos factores (NRC, 1999), por lo que la mayoría de los seguros sólo las cubren sin hacer cálculos formales. En una investigación en la que se abordaron problemas conceptuales y se presentaron refinamientos en la metodología de pérdidas por interrupción de negocios para amenazas naturales en general, se estimaron las pérdidas por interrupción por los cortes de 
energía eléctrica como consecuencia del sismo de Northridge (Rose y Lim, 2002). Por otra parte, en un estudio sobre los impactos del sismo de Nisqually en el sector empresarial, se llevaron a cabo entrevistas con propietarios y gerentes de 107 empresas y se demostró que la recuperación del negocio no sólo está en función de las características de este, sino que también depende de las condiciones del vecindario (Chang y Falit-Baiamonte, 2002). Además, se han estudiado los impactos socioeconómicos que inducen la interrupción de líneas de vida tras los desastres naturales (Chang, 2016) y se han realizado análisis costobeneficio para diversas acciones de resiliencia con la finalidad de reducir la interrupción de negocio (Rose, 2017).

Se tienen pocos modelos de pérdida por interrupción considerando al negocio individual como unidad de análisis. Se ha propuesto una metodología para estimar las pérdidas por interrupción por huracanes que comúnmente cubren las pólizas de seguro contemplando diversos componentes para el tiempo de inactividad y se ha demostrado que el riesgo de interrupción del negocio puede ser significativamente mayor cuando este depende de otros negocios con respecto a cuando no tiene negocios dependientes (Kumar y Guin, 2009). Asimismo, se ha desarrollado un modelo para estimar la pérdida económica por la interrupción en distintos tipos de negocios para los primeros días de haber ocurrido un sismo considerando varias fuentes de interrupción individual y simultáneamente, obteniéndose como resultados que los cortes de energía eléctrica y agua potable pueden causar potencialmente una mayor interrupción de negocio que los daños en el edificio (Chang y Lotze, 2014). No obstante, en ambos modelos no se describen a detalle las fuentes de interrupción ni se identifican las subfuentes derivadas de estas, ni tampoco se presenta un modelo matemático para determinar el tiempo total inactivo del edificio con base en la combinación de los distintos tiempos por las subfuentes con datos de entrada para estas. Otra de las limitantes es que en estas investigaciones no se abordan casos reales, ya que el modelo de Kumar y Guin es calibrado con un negocio hipotético situado en el condado de Hillsborough en Florida con base en la simulación de varios huracanes, mientras que el modelo de Chang y Lotze se aplica para un escenario producido por un sismo hipotético de M7.3 con epicentro en el estrecho de Georgia para el norte de Vancouver, Canadá.

Se tiene poca información sobre pérdida por interrupción de negocios. El Centro de Investigación de Desastres en Delaware ha realizado estudios para obtener datos sobre el impacto a corto y largo plazo en las empresas por las catástrofes (Webb et al., 2002). Los datos de pérdida por interrupción de negocio cubiertas por los seguros en catástrofes históricas sólo están disponibles para las compañías de seguros y estas se limitan a colocar a disposición del público en general guías para el seguro de interrupción de negocio y reclamaciones, como la guía de London Business Interruption Association, LBIA. Las empresas que sufren pérdida por interrupción por algún siniestro también se reservan esa información. Cuando los organismos públicos dan a conocer la cifra de pérdida total a nivel nacional luego de un desastre natural, esta no considera la pérdida por interrupción de negocios. Además, los organismos normalmente sólo publican datos sobre el número de negocios cerrados después de un sismo sin especificar las razones que lo llevaron a ese estado ni dar cifras sobre la pérdida económica en estos; por ejemplo, el Instituto Nacional de Estadística y Geografía informó que, de 2.041 millones de negocios, el 39.3\% suspendieron actividades en algún momento, de los cuales, $43.2 \%$ fue por un día hábil, $23.4 \%$ por dos días, $10.8 \%$ por tres días, y al menos 22.6\% por más de tres días a causa de los sismos de septiembre de 2017 en México (INEGI, 2017).

La presente investigación tiene como objetivo identificar las razones por las que los negocios en la Ciudad de México cerraron tras el sismo ocurrido el 19 de septiembre de 2017 (M7.1) con la finalidad de que esto sea tomado en cuenta por los dueños de las unidades económicas para mejorar sus planes de continuidad y contingencia, así como en los estudios sobre el riesgo sísmico, especialmente en la elaboración de modelos para estimar de manera más precisa la pérdida por interrupción de negocio, IN. Además, se propone un modelo para determinar el tiempo de IN y se proporcionan valores de referencia para los datos de entrada de cada subfuente de interrupción para la Ciudad de México de acuerdo con información obtenida 
de distintos medios de comunicación tras el sismo del 19S de 2017. Finalmente, los conceptos se aplican a un negocio formal hipotético de la CDMX establecido en una edificación de mampostería confinada para determinar el tiempo inactivo de esta debido a un sismo hipotético, donde el tiempo de reparación estructural se determina a través de rendimientos obtenidos por medio de entrevistas a expertos en construcción.

\section{CLASIFICACIÓN DE INTERRUPCIÓN DE NEGOCIO}

La interrupción de negocio, IN, se clasifica en definitiva y temporal, y está en función de diversos factores que se abordan a continuación.

\section{Interrupción definitiva de negocio}

Un estudio que contempló a más de 1400 empresas en todo el mundo demostró que una de las mayores preocupaciones de los directivos es la interrupción de negocio debido a que existen diversas razones por las que un negocio puede fracasar tras un siniestro (Ishii, 2016). Un caso evidente es cuando la edificación colapsa totalmente tras un sismo y la pérdida es total (figura 1). Por otra parte, un negocio puede verse forzado a un cierre definitivo sin antes poder reanudar las actividades empresariales debido a:

- Acumulación de pérdidas por la ausencia de ventas, el pago de nómina a trabajadores y en ocasiones la compensación de daños a terceros.

- Demolición del edificio por daños severos o colapso parcial.

- Elevada pérdida total por los daños en los activos tangibles: elementos estructurales, elementos no estructurales o contenidos del edificio (mobiliario, equipo, stock, entre otros).

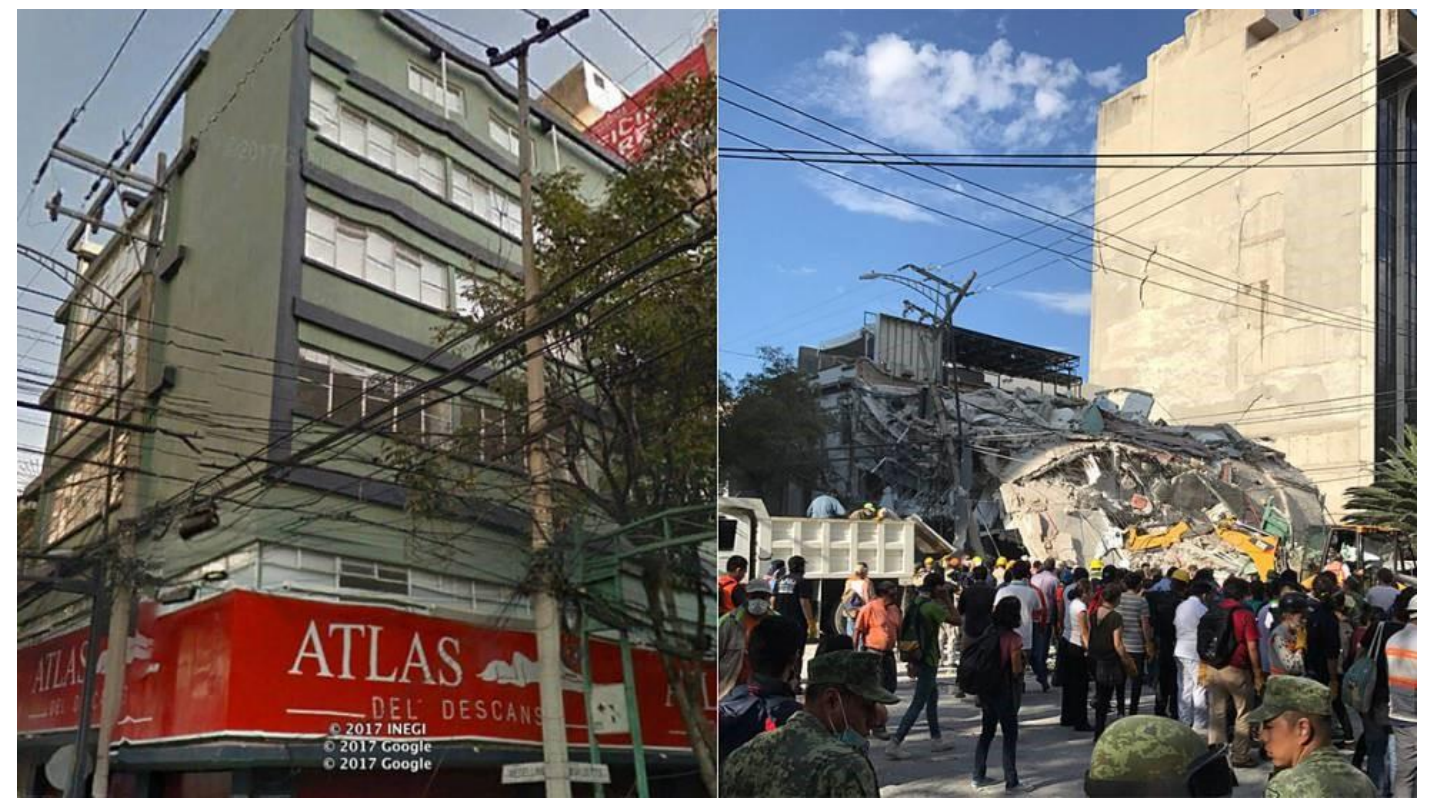

A)

B)

Figura 1. Ejemplo de pérdida total: Edificio de San Luis Potosí y Medellín en la Colonia Roma: A) Antes del sismo del 19S de 2017 y B) Colapso tras el sismo del 19S de 2017. Fuente: Ana Lagos (Usuaria de Twitter) y Google Maps 
Una vez que los negocios reinician las actividades en el inmueble, algunos de ellos no estarán exentos de poder experimentar otros trastornos en especial tras una prolongada interrupción que impactarán en su recuperación (Fernández, 2016), tales como:

- Disminución en las ventas que conllevan a pérdida en la posición de mercado.

- Pérdida de posicionamiento en el mercado asociada a la pérdida de confianza de los clientes o consumidores.

- $\quad$ Pérdida de confianza de los inversionistas.

La recuperación del negocio está ligada a las afectaciones en la zona; por ejemplo, en zonas gravemente afectadas las ganancias disminuyen de forma más notable en ciertos tipos de negocios como los hoteles, aun cuando la propiedad no resulte dañada físicamente. Los daños en las viviendas de los clientes que generan que una de sus principales preocupaciones sea la rehabilitación de su propiedad, o bien, la migración, son otras de las razones por las que los negocios dedicados a la venta de determinados productos sufren una disminución en la cuota de mercado. En consecuencia, se tiene también la probabilidad de que un negocio nunca se pueda recuperar y fracase tiempo después de su reapertura.

\section{Interrupción temporal de negocio}

La interrupción temporal de negocio puede ser total cuando hay una paralización absoluta de las actividades por la inoperatividad del edificio en un periodo determinado o mientras se efectúa la reubicación temporal o definitiva del negocio, o parcial cuando pese a desarrollarse las operaciones del negocio, este no se encuentra en condiciones normales, ya sea cuando se opera por medio del Home Office o por la recuperación de la productividad tras la reanudación de las actividades en el edificio. Estas posibilidades pueden combinarse tal como se muestra en la tabla 1; el modelo que se propone en este documento se enfoca en la combinación 4, dejándose para un futuro refinamiento contemplar las opciones de Home Office y las relocalizaciones del negocio.

Tabla 1. Combinaciones de interrupción temporal de negocio por daños por sismo

\begin{tabular}{|c|c|c|c|c|c|}
\hline \multirow{2}{*}{$\begin{array}{l}\text { No. de } \\
\text { combinación }\end{array}$} & \multicolumn{3}{|c|}{ Total } & \multicolumn{2}{|r|}{ Parcial } \\
\hline & $\begin{array}{l}\text { Inoperatividad del } \\
\text { edificio }\end{array}$ & $\begin{array}{c}\text { Reubicación } \\
\text { temporal }\end{array}$ & $\begin{array}{c}\text { Reubicación } \\
\text { definitiva }\end{array}$ & Home Office & $\begin{array}{c}\text { Recuperación de la } \\
\text { productividad }\end{array}$ \\
\hline 1 & $\mathrm{X}$ & $\mathrm{X}$ & & & $\mathrm{X}$ \\
\hline 2 & $\mathrm{X}$ & & $\mathrm{X}$ & & $\mathrm{X}$ \\
\hline 3 & $\mathrm{X}$ & & & $\mathrm{X}$ & $\mathrm{X}$ \\
\hline 4 & $\mathrm{X}$ & & & & $\mathrm{X}$ \\
\hline
\end{tabular}

En la tabla 2 se muestran algunos ejemplos de negocios situados en la CDMX que experimentaron una interrupción temporal en sus operaciones tras el sismo del 19S de 2017 con M 7.1. La información fue proporcionada por los dueños o empleados de las unidades económicas y se obtuvo a partir de diversas técnicas e instrumentos de recolección de datos; específicamente, en algunos casos se aplicaron entrevistas estructuradas no presenciales, mientras que para otros casos se retomó información anunciada públicamente y difundida por distintos medios de comunicación. Estos negocios cerraron sin que el edificio presentara daños, a excepción del hotel, y aunque esto se debió a varias razones, en la tabla 2 se indica únicamente la fuente predominante.

Obsérvese que, de los nueve negocios, el negocio 1 fue el que mayor tiempo presentó una paralización de actividades con 30 días, ya que por medidas de seguridad los directivos tuvieron que esperar 10 días 
hasta la culminación de labores de rescate de víctimas humanas y 20 días más hasta la finalización de la remoción de escombros tras el colapso del edificio vecino llamado Medellín para poder efectuar la reapertura del negocio, por el contrario, el negocio 3 estuvo cerrado únicamente dos días, ya que en el primer día hubo una suspensión de actividades por el acontecimiento del sismo en horario laboral y al día siguiente se efectuó la inspección post-sísmica del edificio. Por otra parte, el negocio 5 tuvo una interrupción total de 22 días principalmente debido a que el edificio sufrió daños menores y requirió de reparaciones, en tanto, el negocio 8 pudo reabrir tras doce días una vez que se efectuó la evaluación de la seguridad del edificio durante la declaratoria de la emergencia.

Tabla 2. Ejemplos de negocios en la CDMX que cerraron temporalmente por el sismo del 19S de 2017

\begin{tabular}{|c|c|c|c|c|}
\hline $\begin{array}{l}\text { Núm. de } \\
\text { negocio }\end{array}$ & Descripción & Dirección & $\begin{array}{c}\text { Razón predominante de cierre } \\
\text { del negocio }\end{array}$ & $\begin{array}{c}\text { Tiempo } \\
\text { inactivo del } \\
\text { edificio (d) }\end{array}$ \\
\hline 1 & $\begin{array}{l}\text { Sociedad Civil dedicada a la } \\
\text { vinculación y administración de } \\
\text { programas de becarios }\end{array}$ & $\begin{array}{l}\text { San Luis Potosí 199, Col. Roma } \\
\text { Norte, Cuauhtémoc, C.P. 06700, } \\
\text { Ciudad de México }\end{array}$ & $\begin{array}{c}\text { Colapso de un edificio vecino } \\
\text { en el que hubo víctimas } \\
\text { humanas }\end{array}$ & 30 \\
\hline 2 & $\begin{array}{l}\text { Oficinas de empresa dedicada a la } \\
\text { fabricación y comercialización de } \\
\text { tableros de madera (alta densidad, } \\
\text { enchapados, MDF, etc.) }\end{array}$ & $\begin{array}{c}\text { Jaime Balmes No. 8, Col. Polanco, } \\
\text { Miguel Hidalgo. C.P. 11510, } \\
\text { Ciudad de México }\end{array}$ & $\begin{array}{l}\text { Complicaciones en las vías de } \\
\text { acceso al inmueble }\end{array}$ & 4 \\
\hline 3 & $\begin{array}{l}\text { Empresa financiera dedicada a } \\
\text { otorgar créditos de consumo. }\end{array}$ & $\begin{array}{c}\text { Periférico Sur 5000, Insurgentes } \\
\text { Cuicuilco, Coyoacán, C.P. 04369, } \\
\text { Ciudad de México }\end{array}$ & $\begin{array}{l}\text { Inspección post-sísmica del } \\
\text { edificio }\end{array}$ & 2 \\
\hline 4 & $\begin{array}{l}\text { Institución educativa en la que se } \\
\text { imparte Ingeniería Civil }\end{array}$ & $\begin{array}{l}\text { Juan de Dios Bátiz S/N, Adolfo } \\
\text { López Mateos, Gustavo A. Madero, } \\
\text { C.P. 07738, Ciudad de México }\end{array}$ & $\begin{array}{l}\text { Inspección post-sísmica del } \\
\text { edificio }\end{array}$ & 5 \\
\hline 5 & Hotel & $\begin{array}{c}\text { Calz. de Tlalpan 1507, Portales Nte, } \\
\text { Benito Juárez, C.P. 03300, Ciudad } \\
\text { de México }\end{array}$ & Daños menores en el edificio & 22 \\
\hline 6 & Cine & $\begin{array}{c}\text { Avenida prolongación Paseo de la } \\
\text { Reforma 400, Santa Fe, Álvaro } \\
\text { Obregón, C.P. 01210 Ciudad de } \\
\text { México }\end{array}$ & $\begin{array}{l}\text { Inspección post-sísmica del } \\
\text { edificio }\end{array}$ & 6 \\
\hline 7 & $\begin{array}{l}\text { Museo público dedicado a presentar } \\
\text { exposiciones de arte contemporáneo } \\
\text { internacional }\end{array}$ & $\begin{array}{c}\text { Av. Paseo de la Reforma 51, } \\
\text { Polanco, Bosque de Chapultepec I } \\
\text { Secc, Miguel Hidalgo, C.P. } 11580 \text {, } \\
\text { Ciudad de México }\end{array}$ & $\begin{array}{l}\text { Evaluación de la seguridad } \\
\text { estructural del edificio durante } \\
\text { la declaratoria de emergencia }\end{array}$ & 12 \\
\hline 8 & $\begin{array}{l}\text { Museo cultural para exhibir objetos } \\
\text { artísticos }\end{array}$ & $\begin{array}{l}\text { Av. Juárez S/N, Centro Histórico de } \\
\text { la Ciudad de México, Cuauhtémoc, } \\
\text { C.P. 06050, Ciudad de México }\end{array}$ & $\begin{array}{l}\text { Evaluación de la seguridad } \\
\text { estructural del edificio durante } \\
\text { la declaratoria de emergencia }\end{array}$ & 12 \\
\hline 9 & Teatro & $\begin{array}{l}\text { Calz. Manuel Villalongín 15, Col. } \\
\text { Renacimiento, Cuauhtémoc, C.P. } \\
\text { 06500, Ciudad de México }\end{array}$ & $\begin{array}{l}\text { Evaluación de la seguridad } \\
\text { estructural del edificio durante } \\
\text { la declaratoria de emergencia }\end{array}$ & 11 \\
\hline
\end{tabular}

En la figura 2 se muestra la ubicación de los nueve negocios en el mapa de zonificación geotécnica de la Ciudad de México del Reglamento de Construcciones para el Distrito Federal (RCDF, 2017). Puede observarse que el negocio 7 pertenece a la Zona II (Transición), mientras que, por ejemplo, los negocios 1 , 6 y 8 se encuentran situados en la Zona III (Lacustre) y los negocios 2 y 3 en la Zona I (Lomas). Por otra parte, en la figura 3 se muestra el edificio en el que se encuentra establecida cada unidad económica. No se dispone de información acerca de que si los edificios han sufrido daños por sismos previos o sobre si han sido rehabilitados. Además, en la mayoría de los casos tampoco se conoce el año en el que fueron construidos. Se tiene un registro de que, por ejemplo, el negocio 7 fue inaugurado el 29 de mayo de 1981, en tanto, el Palacio de Bellas Artes, inmueble que alberga el negocio 8, fue concluido e inaugurado el 29 de noviembre de 1934. 


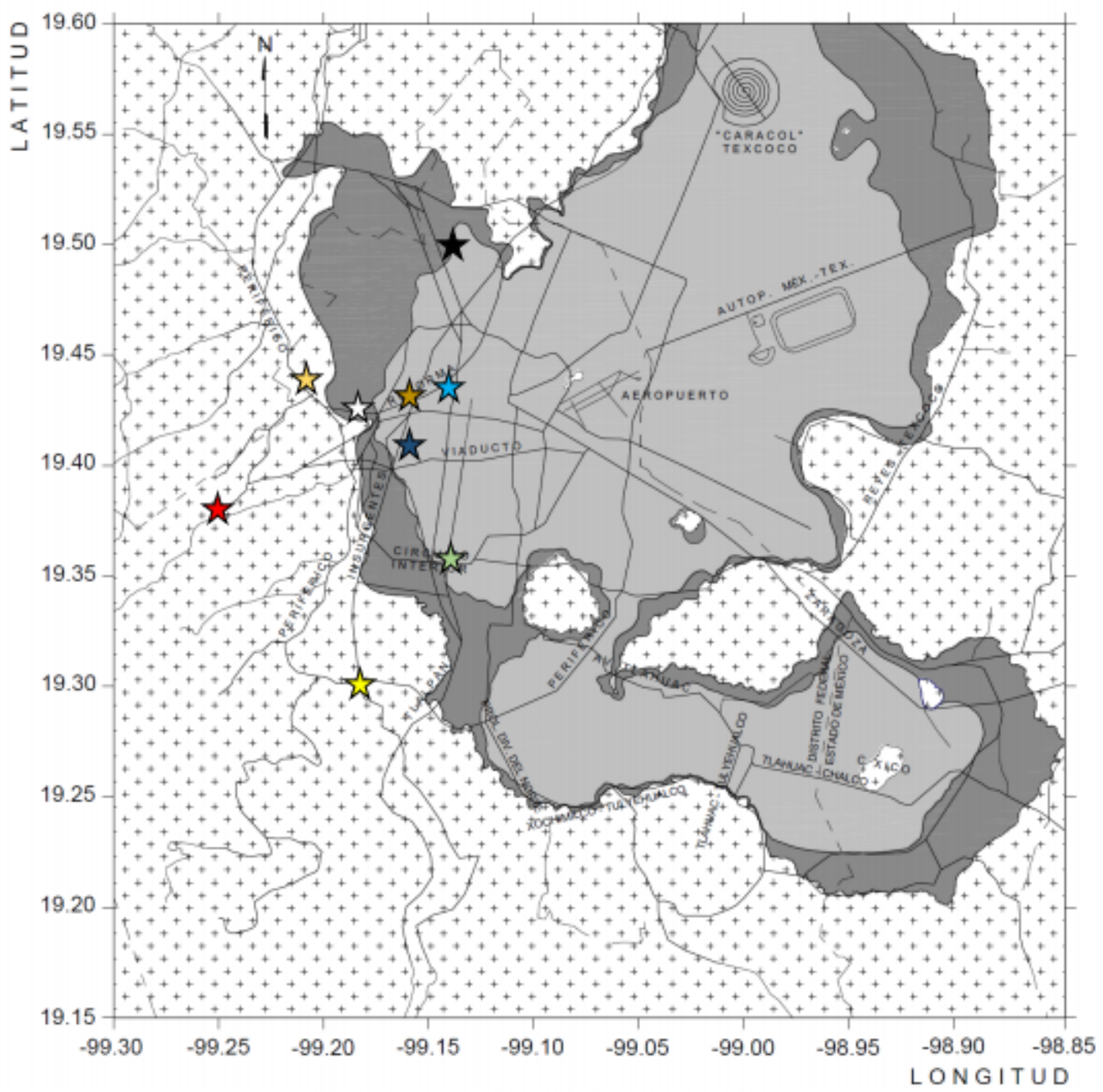

\section{Escala gráfica}

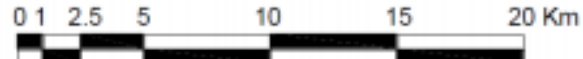

\section{Simbología}

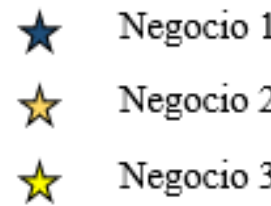

\. Negocio 4
ฟh Negocio 5
ל. Negocio 6

$\begin{array}{ll}\text { h } & \text { Negocio } 7 \\ \text { h } & \text { Negocio } 8 \\ \text { ‘ } & \text { Negocio } 9\end{array}$

Zona I

Zona II

Zona III

Figura 2. Ubicación de los negocios mostrados en la tabla 2 en el mapa de zonificación geotécnica de la Ciudad de México. Fuente: Elaboración propia con base en el Reglamento de Construcciones para el

Distrito Federal del 2017 


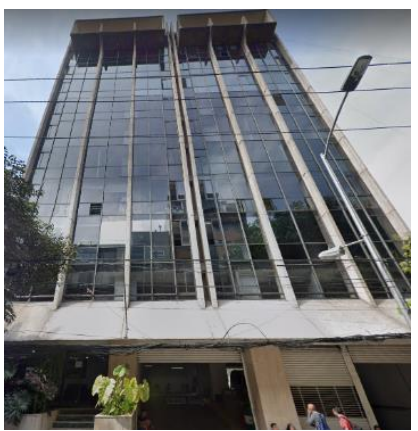

A)

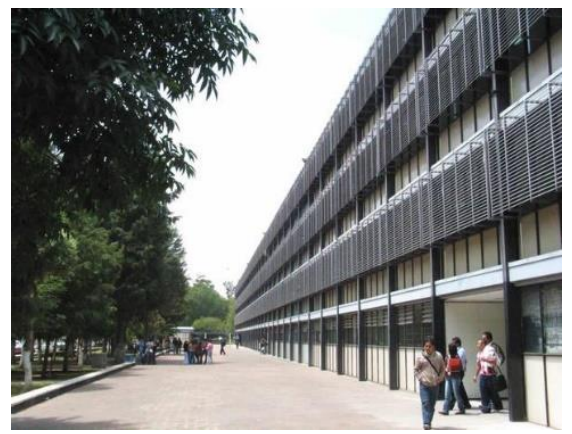

D)

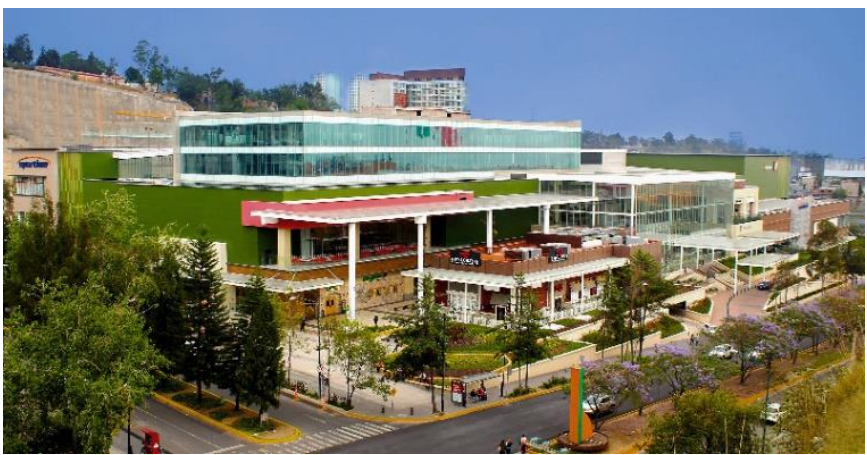

F)

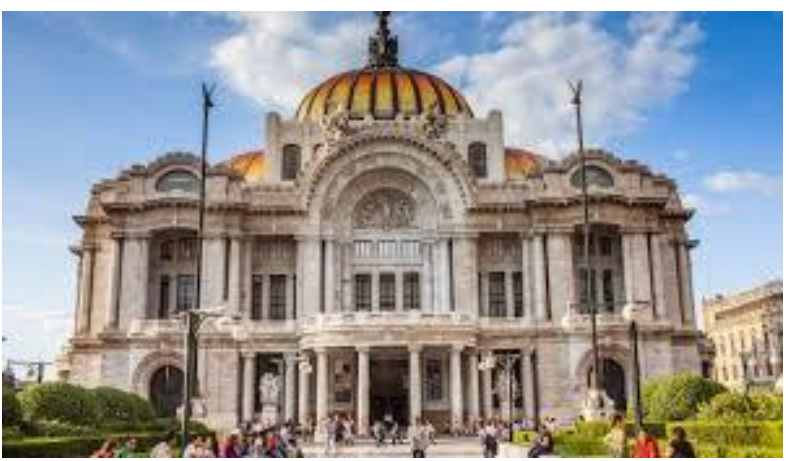

$\mathrm{H})$

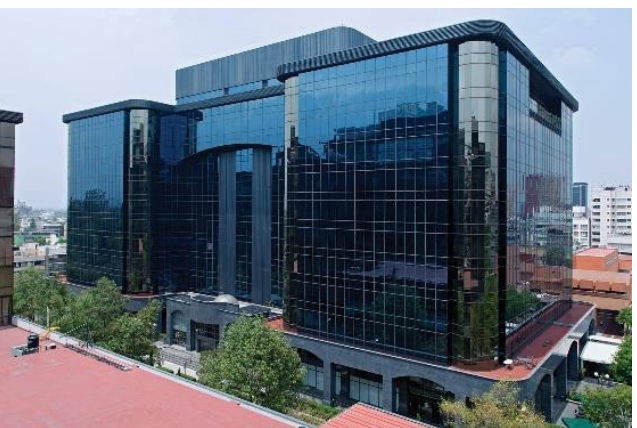

B)

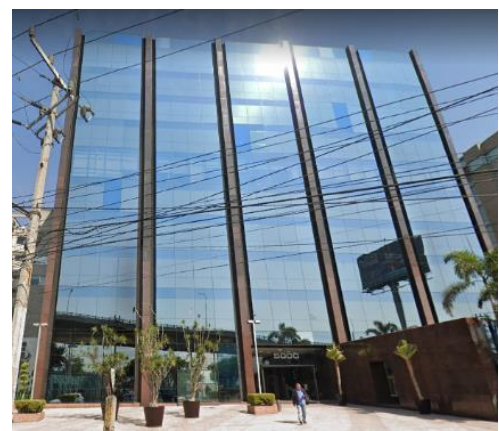

C)

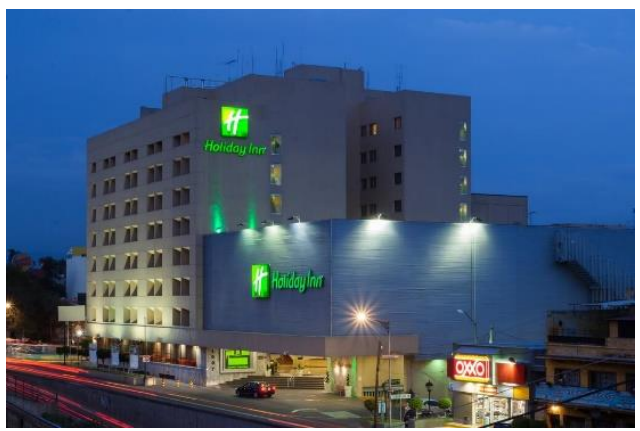

E)

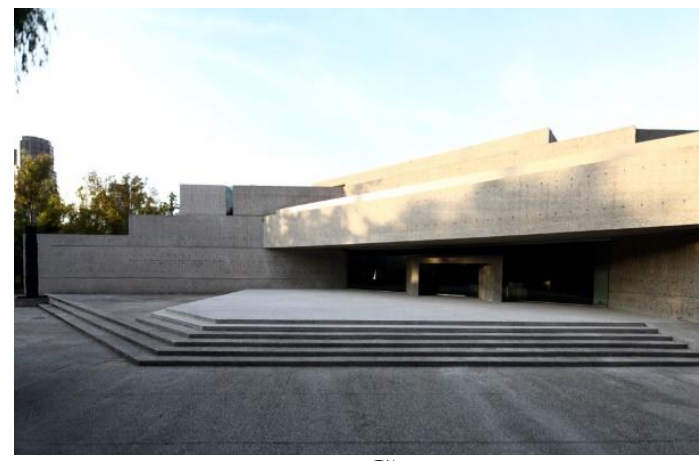

G)

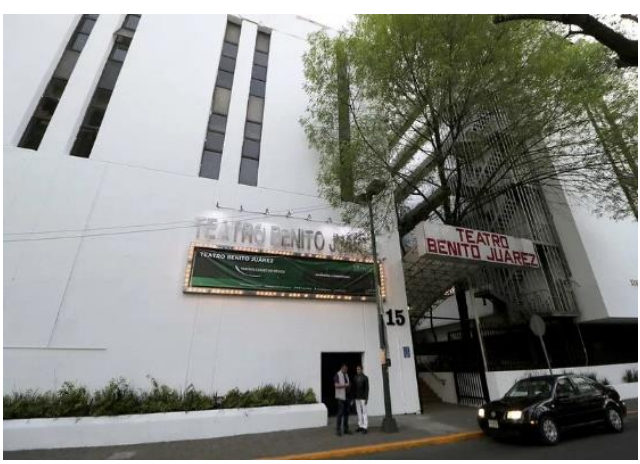

I)

Figura 3. Edificios en los que se encuentran establecidos los negocios mostrados en la tabla 2:

A) Negocio 1, B) Negocio 2, C) Negocio 3, D) Negocio 4, E) Negocio 5, F) Negocio 6, G) Negocio 7, H) Negocio 8, I) Negocio 9. Fuente: Google 
Durante el tiempo inactivo del edificio, dependiendo del tipo de negocio, este sufre una ausencia o minoración de ingresos, por ejemplo, por la suspensión de ventas, además de que puede seguir teniendo costos o gastos como los pagos de nómina a los trabajadores, de renta del inmueble o del servicio de energía eléctrica, por consiguiente, no sólo puede dejar de tener ganancias, sino que además puede ver reflejada una pérdida en el reporte financiero. Incluso, tras la reapertura del negocio los ingresos obtenidos pueden seguir siendo menores a los gastos incurridos por un periodo determinado, por ejemplo, por la disminución de las ventas debido a una pérdida en la posición o el posicionamiento de mercado, o a causa de un aumento en los gastos operativos (comercialización, alquiler, administración, entre otros). Debido a que comúnmente no se tiene acceso a información explícita sobre ingresos y gastos de los negocios, para fines de esta investigación se emplea la definición estándar de pérdida contable, por medio de la ecuación 1 y se asume que esta es estimada por el respectivo personal con base en un estado de resultados del negocio.

$P=I-G \leftrightarrow G>I$

donde $I$ son los ingresos obtenidos por el negocio y $G$ son los gastos incurridos, ambos en el tiempo de interrupción del negocio. Si en el estado de resultados los ingresos son mayores a los gastos, pero el lucro sigue siendo menor al que se tendría si el sismo no hubiera ocurrido según los estados financieros, se tiene que el negocio experimenta una disminución en las utilidades. Esto ocurre en ocasiones principalmente durante el tiempo de recuperación del negocio.

\section{MODELO DE TIEMPO DE INTERRUPCIÓN DE NEGOCIO POR SISMO}

Como consecuencia de la ocurrencia del sismo del 19S de 2017, a menudo un edificio quedó inoperativo por un tiempo determinado producto de diversas razones, lo cual propició un cierre del negocio. Cuando el inmueble estuvo nuevamente en condiciones de servicio, se procedió a la reapertura de la unidad económica, sin embargo, comúnmente a esta le tomó un tiempo recuperar la productividad que tenía antes del siniestro. Por consiguiente, el tiempo total de interrupción de un negocio, $t_{T I N}$, puede determinarse con la ecuación 2.

$t_{T I N}=t_{T I E}+t_{R P}$

donde $t_{T I E}$ es el tiempo total inactivo de la edificación y $t_{R P}$ es el tiempo de recuperación de la productividad del negocio.

La ecuación 2 puede aplicarse a toda clase de negocio que esté establecido en una edificación de cualquier tipo de sistema estructural y material constructivo, y se supone que la unidad económica no depende significativamente de otros negocios para su funcionamiento y que no tiene negocios que dependan de ella. En este trabajo no se abordará con un modelo el cálculo de $t_{R P}$, ya que no se dispone de información sobre la recuperación de los negocios, por lo tanto, se considerará que el $t_{T I N}$ está definido únicamente por el $t_{T I E}$, tal como muchas aseguradoras lo asumen.

En la tabla 3 se muestran las fuentes de interrupción derivadas del sismo del 19S de 2017 que se contemplan en el modelo de IN (figura 4), clasificadas en cuatro categorías principales: Protocolos de seguridad iniciales (PSI), Suspensión de servicios públicos de suministro (SSPS), Efectos de vecindario (EV) y Daños en los componentes del edificio (DCE), donde las primeras tres se consideran como efectos indirectos en el edificio. Cada una de ellas se divide en varias subfuentes de interrupción que 
individualmente pueden generar un tiempo de inactividad en el edificio del negocio, sin embargo, el $t_{T I E}$ es resultado de la combinación de los distintos tiempos, lo cual se aborda enseguida.

El modelo de tiempo total inactivo de la edificación se muestra en la figura 4 y tiene como inicio la ocurrencia de un sismo. Se verifica en paralelo si se presenta una interrupción de negocio por Protocolos de seguridad iniciales (PSI), Suspensión de servicios públicos de suministro (SSPS) o Efectos de vecindario $(\mathrm{EV})$ tras el sismo. Si la línea de flujo se dirige a la respuesta negativa para cada decisión, entonces $t_{A}, t_{B}$, y $t_{C}$, que se definen respectivamente como los tiempos inactivos del edificio resultantes por PSI, SSPS y $\mathrm{EV}$ toman un valor de cero, de lo contrario, se leen las variables $t_{A}, t_{B}$ y $t_{C}$.

Enseguida se calcula $t_{D}$, definido como el valor máximo de los tiempos inactivos por PSI, SSPS y EV con la ecuación,

$t_{D}=\max \left(t_{A}, t_{B}, t_{C}\right)$

Si no hay una interrupción de negocio por Daños en los componentes del edificio (DCE), el tiempo inactivo por DCE, $t_{E}$, se hace cero, mientras que para el caso opuesto se lee dicha variable. Posteriormente el tiempo total inactivo de la edificación se calcula con la ecuación,

$t_{T I E}=\max \left(t_{D}, t_{E}\right)$

Tabla 3. Fuentes de interrupción de negocio observadas tras el sismo del 19S de 2017

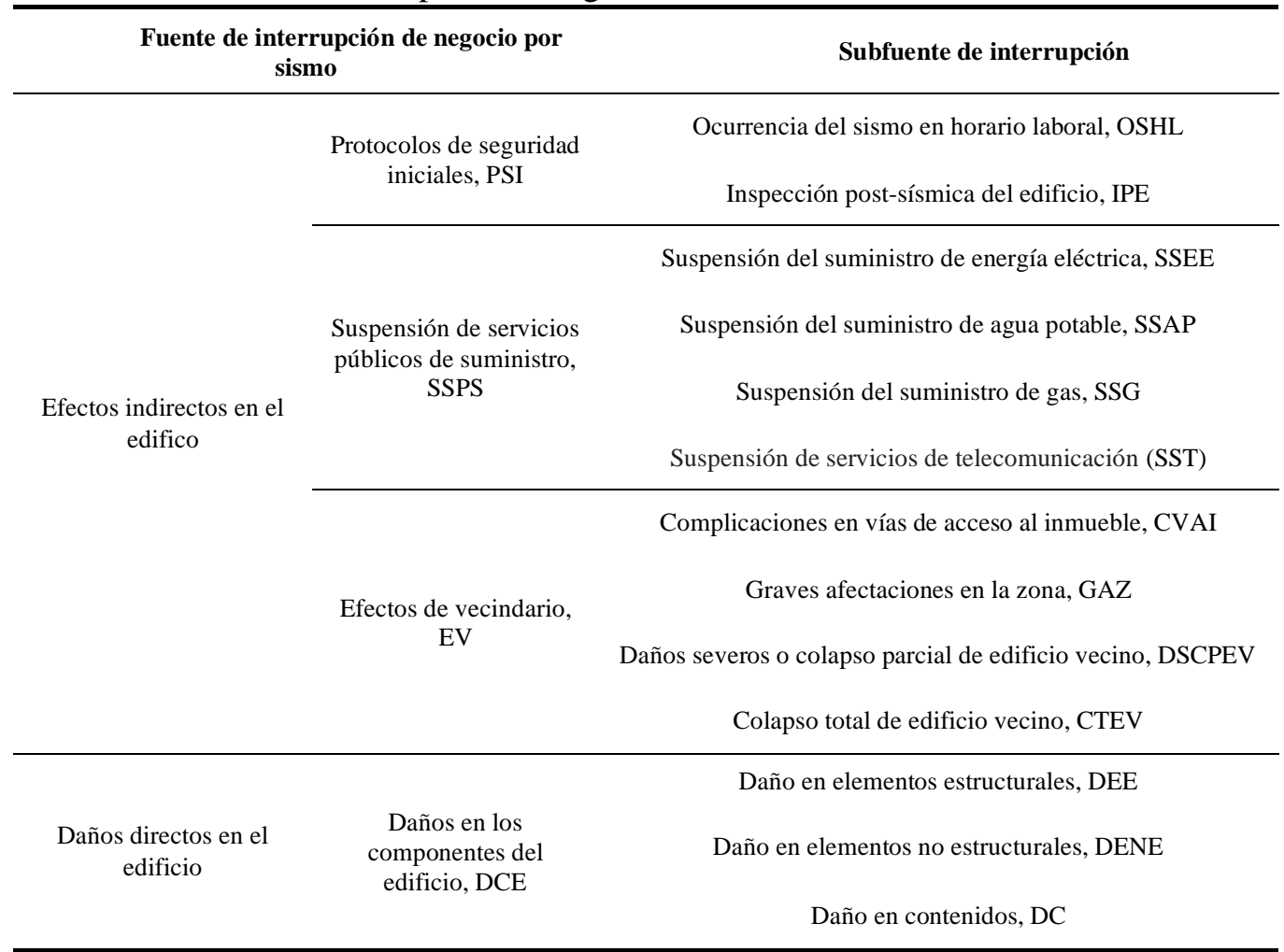

Debido a que todos los negocios presentan un nivel de resistencia a la interrupción, los dueños o directivos podrían comenzar con la planeación para la rehabilitación de daños a la propiedad sin esperar a que los servicios públicos de suministro sean restaurados por los organismos competentes o a que las 
condiciones de vecindario se mejoren. Dadas las incertidumbres sobre las variables del modelo mostrado en la figura 1 , se considera que $t_{A}, t_{B}, t_{C}$ y $t_{E}$ son tiempos medidos desde la ocurrencia del sismo hasta la finalización de los protocolos de seguridad iniciales, la restauración de los servicios públicos, el restablecimiento del vecindario y la rehabilitación de los componentes del edificio o la decisión del dueño para volver a operar ante daños que no pongan en peligro la seguridad de los ocupantes del edificio, respectivamente.

El tiempo inactivo del edificio por cada fuente de interrupción se puede calcular de forma independiente con los procesos 1, 2, 3 y 4 que se describen a continuación. Para tener valores de referencia para los datos de entrada para el tiempo de inactividad que genera cada subfuente, se ha recabado información de distintos medios de comunicación con base en lo expuesto por Ingenieros Civiles, empresas proveedoras de servicios públicos, autoridades gubernamentales, entre otros.

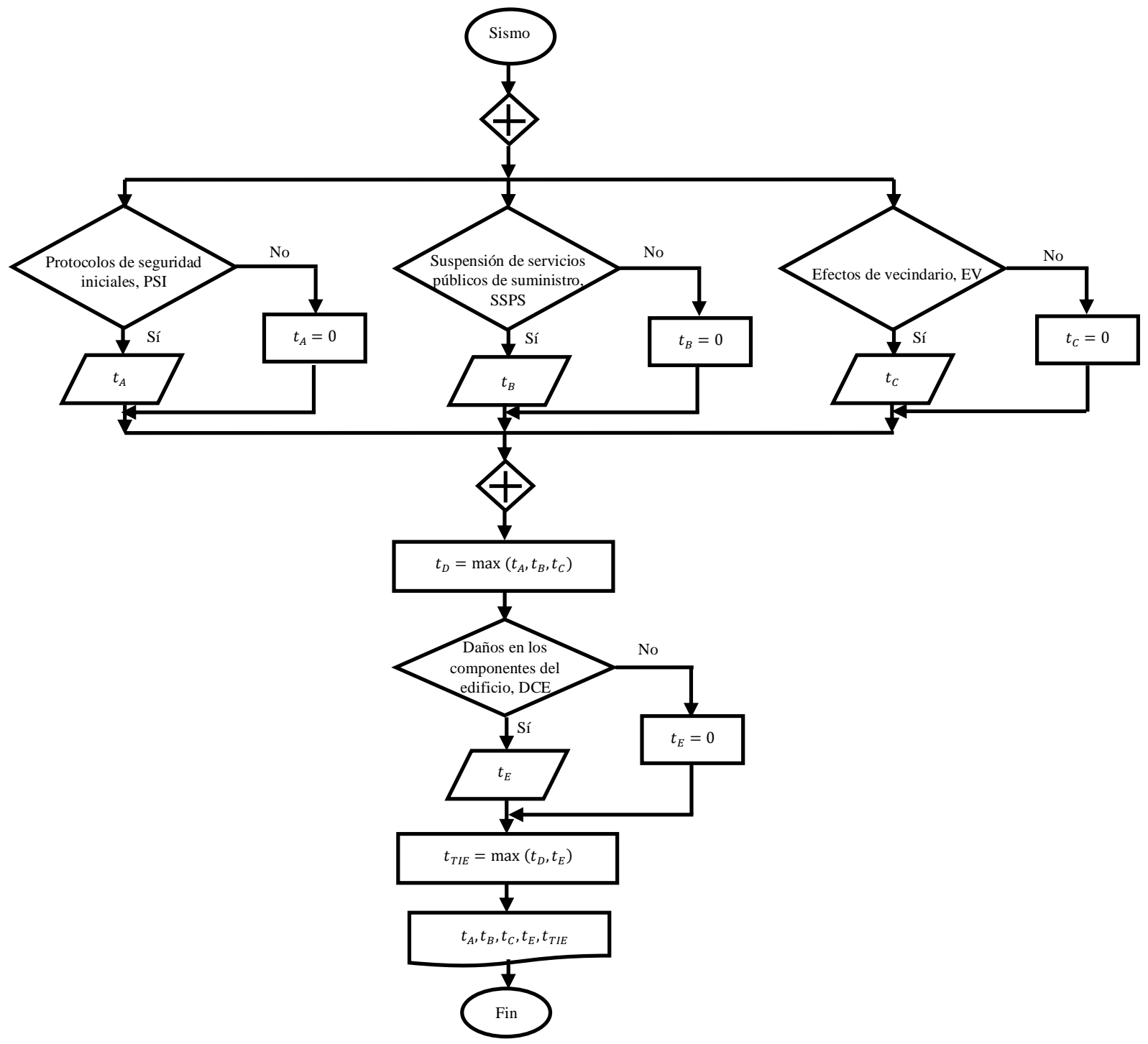

Figura 4. Modelo de tiempo total inactivo de la edificación 


\section{Proceso 1: Cálculo del tiempo inactivo del edificio por Protocolos de seguridad iniciales, $\boldsymbol{t}_{\boldsymbol{A}}$}

El proceso 1 se muestra en la figura 5. El edificio puede quedar inoperativo por la Ocurrencia del sismo en horario laboral (OSHL), así como por la Inspección post-sísmica del edificio (IPE), (Gama et al., 2012). Los tiempos de inactividad por las subfuentes OSHL y IPE, $t_{1}$ y $t_{2}$ se combinan dando como resultado el tiempo inactivo del edificio por protocolos de seguridad iniciales, $t_{A}$.

$$
t_{A}=\max \left(t_{1}, t_{2}\right)
$$

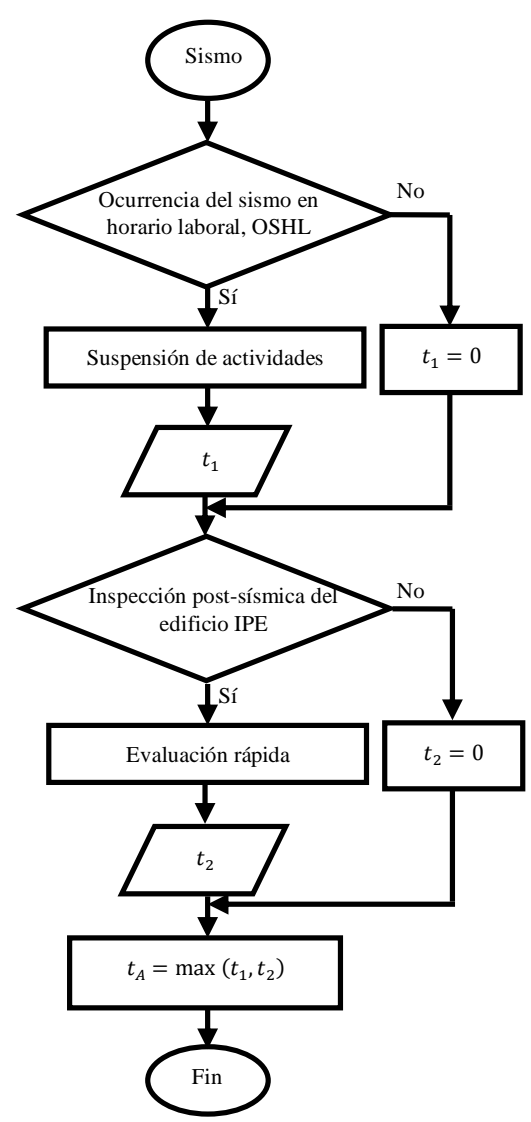

Figura 5. Diagrama de flujo del "Proceso 1: Cálculo del tiempo inactivo del edificio por Protocolos de seguridad iniciales, $t_{A}$ "

El sismo del 19S de 2017 ocurrió un martes a las 13:14:40 horas (hora del centro México) en la jornada de trabajo de la mayoría de los negocios. Se observó que una gran cantidad de unidades económicas suspendió sus operaciones por el resto del día tras la evacuación del edificio y hasta nuevo aviso, a excepción del aeropuerto y algunos hospitales de la CDMX que tuvieron una paralización de actividades únicamente por algunas horas, debido a que las revisiones indicaron que no existían daños directos ni efectos indirectos en los inmuebles correspondientes que ponían en riesgo la seguridad de los ocupantes.

La inspección post-sísmica del edificio se realizó para determinar únicamente si este podía ocuparse o no de inmediato con la finalidad de evitar víctimas humanas ante las futuras réplicas o para prevenir pérdidas materiales evaluándose el riesgo de colapso del edificio e identificando si es que había daños en los componentes del edificio. Fue común que para poder efectuar la reapertura de negocios formales se 
requiriera de un dictamen tras una evaluación inicial del estado de la edificación en el que el inmueble se clasificó como "Edificación y área segura / Riesgo bajo". Las etapas de la inspección post-sísmica fueron:

- Solicitud del servicio

- Trabajos de campo para la evaluación rápida del edificio

- Trabajos de gabinete para la elaboración y emisión de dictamen

- Colocación de dictamen o carteles en el edificio

En ocasiones se llevó a cabo una evaluación simplificada en lugar de una inspección post-sísmica, en la cual se clasificó el nivel de daño global de la estructura y se identificó si ocurrieron otros daños en elementos como vidrios, acabados, plafones, fachadas, bardas, pretiles, escaleras, elevadores e instalaciones. Esta evaluación también se efectuó en edificaciones que se consideraron con dudas tras la inspección postsísmica.

Debido a los primeros niveles de evaluación de la seguridad de los edificios, que se realizaron de acuerdo con la legislación vigente, varios inmuebles quedaron inactivos hasta una semana dependiendo de los recursos del propietario para contratar a ingenieros o arquitectos, o de la disponibilidad de estos profesionistas (tabla 4), (ReNE, 2018). Por ejemplo, la empresa de entretenimiento Cinépolis informó que 25 de sus complejos cerraron alrededor de seis días. Sin embargo, hubo casos excepcionales en los que los dictámenes de seguridad estructural se emitieron hasta 15 días después de la catástrofe, tales como en escuelas públicas de la CDMX, prolongándose notablemente el tiempo de interrupción de los negocios e inclusive se registraron casos en los que estos cerraron por un periodo mayor a causa de que los dictámenes preliminares fueron imprecisos.

Tabla 4. Primeros niveles de evaluación estructural acorde con el sismo del 19S de 2017 en México

\begin{tabular}{|c|c|c|c|}
\hline Nivel de Evaluación & Personal que efectuó la evaluación & $\begin{array}{l}\text { Período de realización } \\
\text { aproximado }\end{array}$ & $\begin{array}{c}\text { Duración promedio } \\
\text { de los trabajos de } \\
\text { campo (h) }\end{array}$ \\
\hline $\begin{array}{l}\text { EDAN (Evaluación de } \\
\text { daños y análisis de } \\
\text { necesidades) o } \\
\text { Inspección post-sísmica }\end{array}$ & $\begin{array}{c}\text { Protección Civil (a nivel no profesional e } \\
\text { inicialmente sólo en casos excepcionales), } \\
\text { Ingenieros Civiles y Arquitectos locales, brigadas } \\
\text { voluntarias conformadas por estos profesionistas que } \\
\text { las dirigieron y estudiantes, y DRO y CSE (en casos } \\
\text { especiales). }\end{array}$ & $\begin{array}{c}\text { Durante el día del sismo } \\
\text { y los tres días } \\
\text { posteriores a la } \\
\text { ocurrencia de este }\end{array}$ & {$[0.25,0.5]$} \\
\hline Evaluación Simplificada & $\begin{array}{l}\text { Equipos dirigidos por un Ingeniero Civil o } \\
\text { Arquitecto, y DRO y CSE (en casos especiales). }\end{array}$ & $\begin{array}{c}\text { Durante el día del sismo } \\
\text { y la primer semana } \\
\text { posterior a la ocurrencia } \\
\text { de este }\end{array}$ & {$[0.5,1]$} \\
\hline
\end{tabular}

\section{Proceso 2: Cálculo del tiempo inactivo del edificio por suspensión de servicios públicos, $t_{B}$}

En el proceso 2 (figura 6), la interrupción de negocio puede darse por la Suspensión del suministro de energía eléctrica (SSEE), la Suspensión del suministro de agua potable (SSAP), la Suspensión del suministro de gas (SSG) y la Suspensión de servicios de telecomunicación (SST).

Si las operaciones empresariales no pueden desarrollarse hasta que el edificio cuente nuevamente con energía eléctrica, agua potable, gas o servicios de telecomunicación, entonces el tiempo inactivo del edificio por la suspensión de servicios públicos de suministro, $t_{B}$, se calcula con la ecuación,

$t_{B}=\max \left(t_{3}, t_{4}, t_{5}, t_{6}\right)$ 
donde $t_{3}, t_{4}, t_{5}$ y $t_{6}$ son los tiempos de inactividad de forma respectiva por las subfuentes SSEE, SSAP, SSG y SST.

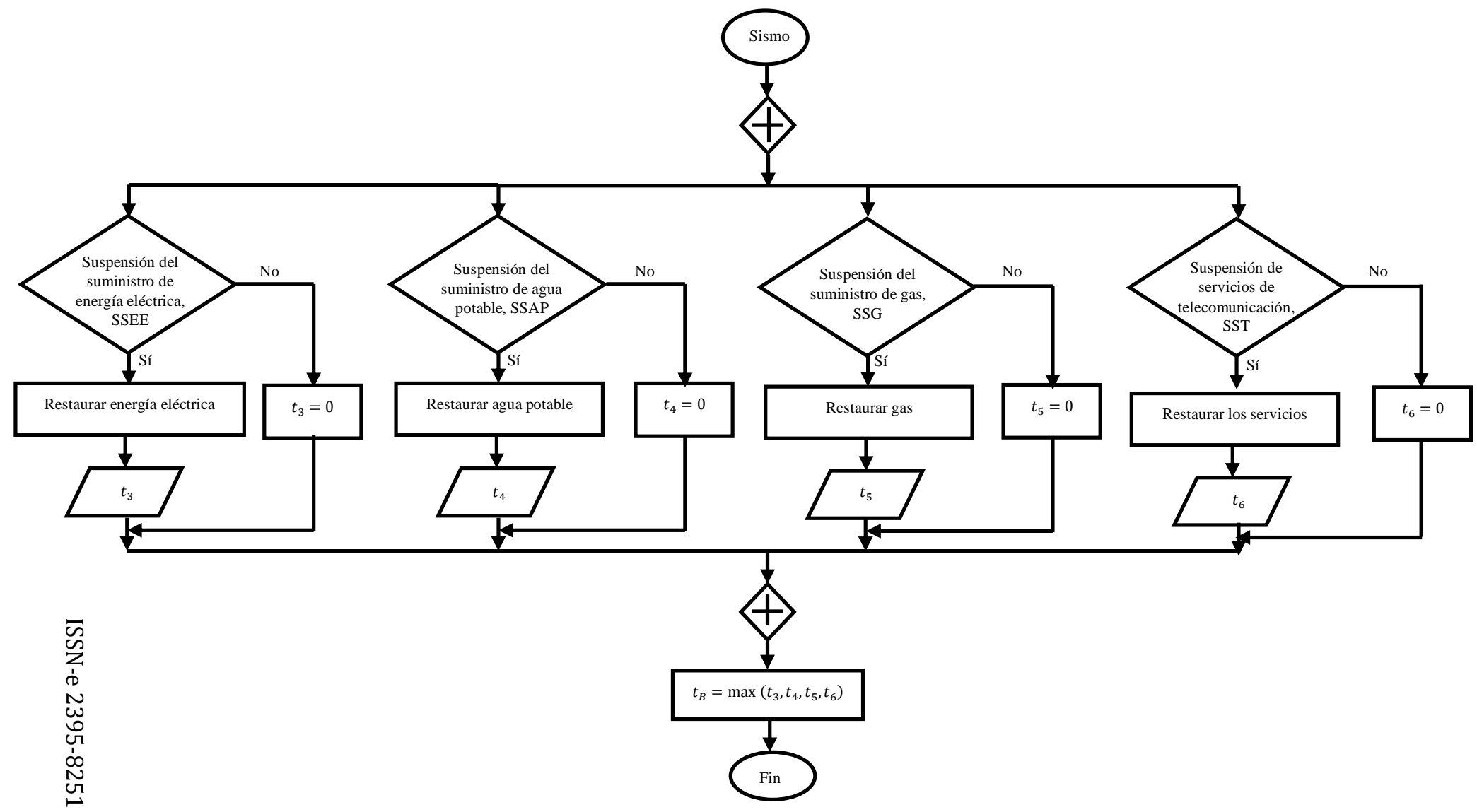

Figura 6. Diagrama de flujo del "Proceso 2: Cálculo del tiempo inactivo del edificio por suspensión de servicios públicos, $t_{B} "$

De acuerdo con la Comisión Federal de Electricidad (CFE), el sismo del 19S de 2017 afectó a 4.8 millones de sus clientes, debido a que se produjeron algunos daños en el sistema de infraestructura de energía eléctrica, entre ellos caída de postes y cables, un estallamiento de transformadores en la Noria, CDMX y afectaciones considerables en la subestación de Yautepec, Morelos (figura 7). Con corte a las 19:00 horas y a las 22:00 horas del día de la ocurrencia del sismo el servicio había sido restablecido de manera correspondiente para el $58 \%$ y el $73 \%$ del total de los afectados, mientras que para el día siguiente con corte a las 8:00 horas y a las 21:00 horas el servicio se había restaurado de forma respectiva para el $92 \%$ y $95 \%$. Asimismo, por indicaciones de autoridades de Protección Civil, el servicio no fue reanudado en zonas de labores de rescate de víctimas humanas hasta la culminación de dichas actividades con la finalidad de evitar riesgos para los rescatistas y la población en general, las cuales tuvieron una duración aproximada de 15 días, siendo necesario el despliegue de 54 torres de iluminación para tales fines. Por otra parte, CFE desplazó 32 plantas de emergencia para hospitales e instalaciones de emergencia para que estos pudieran seguir operando inmediatamente después del sismo. 
La falta de energía eléctrica produjo efectos negativos en una gran cantidad de negocios. Por ejemplo, la empresa Oxxo cerró el $30 \%$ de sus sucursales en la capital de México por esta razón. Se registró que dos días después del sismo 267 tiendas de las 300 que habían dejado de operar efectuaron su reapertura.
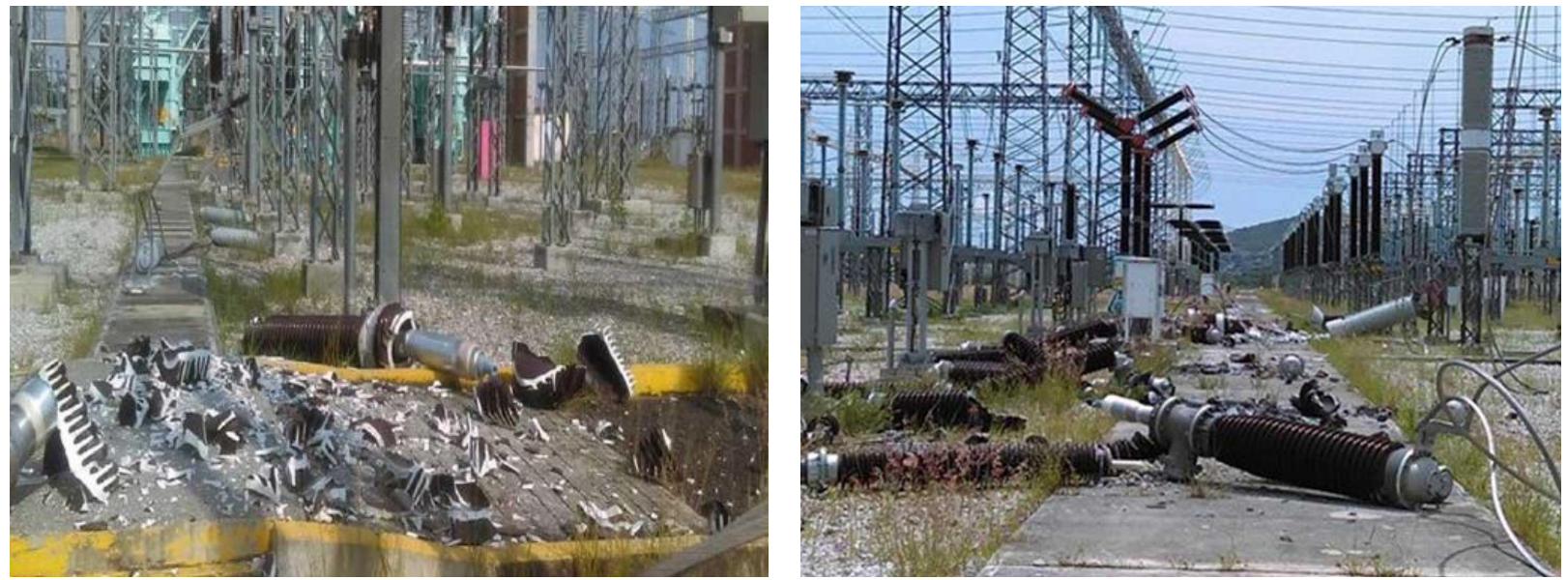

Figura 7. Daños en la subestación Yautepec, Morelos ocasionados por el sismo del 19S de 2017. Fuente: Excélsior

De acuerdo con CONAGUA, el sismo de M. 7.1 dejó en total un saldo aproximado de seis millones de personas damnificadas por corte de agua, producto de que la infraestructura de agua potable sufrió varias afectaciones, entre ellas 1, 22 y 13 fugas en acueducto de forma respectiva en los ramales de Peñón-Texcoco, Tláhuac-Nezahualcóyotl y Mixquic-Santa Catarina, daños en los equipos electromecánicos de 11 pozos del primer ramal citado, así como la caída de 21 transformadores y 42 bombas quemadas en la Ciudad de México. Además, se documentó que las fugas ocasionadas por este evento se presentaron en todas las alcaldías, no obstante, el mayor número de daños se originó en el Sur-Oriente de la CDMX. Particularmente, en Iztacalco, Iztapalapa, Tláhuac y Xochimilco se registraron de manera correspondiente 3, 32, 15 y 11 fugas en la red primaria y 64, 291, 100 y 142 fugas en la red secundaria. Dentro de las detectadas por el SACMEX (figura 8), se observaron impactos en las caras adyacentes de los tubos de concreto que ocasionaron la ruptura en los puntos de unión de tramos de la tubería o separación entre ellos, rupturas en el cuerpo del tubo de tuberías de asbesto-cemento y separación entre tubos adyacentes que dañaron los empaques en las tuberías de acero (Ayala et al., 2019).

Las reparaciones efectuadas por SACMEX se hicieron mediante la colocación de silletas o empaques. Por la importancia social y económica que tiene el suministro de agua potable, aproximadamente cuatro días después del sismo del 19S de 2017 algunas personas afectadas comenzaron a recibir el servicio de manera provisional básicamente a través de pipas enviadas por el gobierno, sin embargo, de acuerdo con los testimonios de los habitantes el agua recibida no fue suficiente para abastecer a todos los damnificados, lo cual generó un caos a tal grado de que las pipas comenzaron a ser secuestradas, por lo que se vieron forzados a contratar el servicio con empresas privadas. Incluso existe evidencia de que en varias partes de las zonas de Iztapalapa, Tláhuac y Xochimilco se tuvo una suspensión del suministro de hasta por más de 10 días. Por otra parte, a más de 10 meses del sismo la Comisión para la Reconstrucción de Ciudad de México reportó un avance del $40 \%$ en la reparación de la infraestructura hidráulica de drenaje y agua potable, de modo que el servicio no se encontraba normalizado aún.

Con respecto a los servicios de telecomunicación, el día que aconteció el sismo las redes móviles de voz colapsaron por algunas horas, debido a que la mayoría de la población se comunicó por voz 
principalmente con sus familiares para informarse entre sí sobre el estado de salud mental y físico en el que se encontraban y para conocer si sus propiedades habían presentado afectaciones, pese a que se recomendó que esto se efectuará a través del envío de mensajes de texto o con aplicaciones de chat. Por el contrario, no se registró un colapso de las redes móviles de datos.

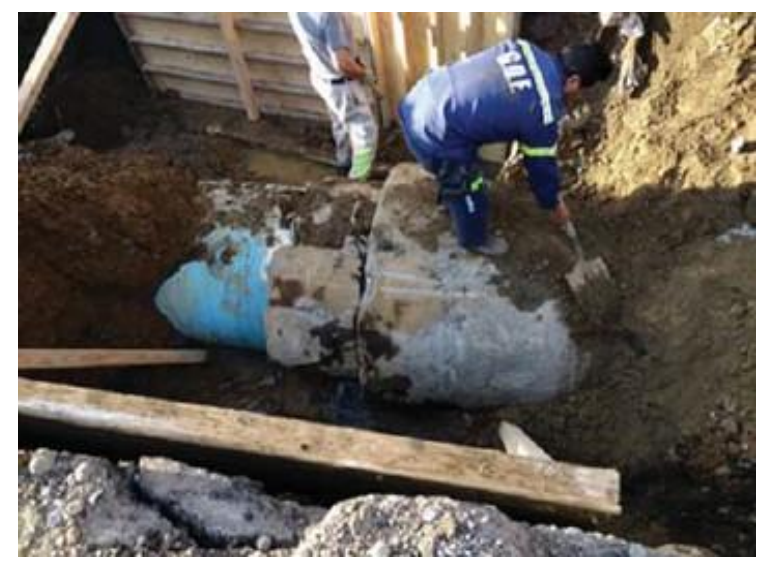

A)

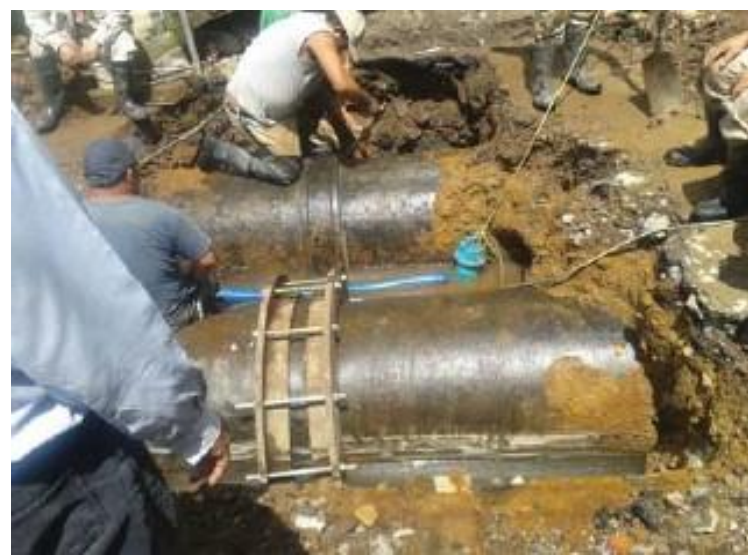

B)

Figura 8. Fugas en red primaria de la Ciudad de México derivadas del sismo del 19S de 2017: A) Tubería de asbesto-cemento de 48 in ubicada en Tláhuac y B) Tubería de acero de 30 in situada en Xochimilco.

Fuente: SACMEX. Tomado de: Ayala et al., 2019

Por otra parte, el gobierno de la CDMX reportó que durante los primeros tres días tras el sismo se habían controlado más de mil fugas de gas, las cuales algunas ocasionaron explosiones e incendios. Asimismo, la empresa Gas Natural Fenosa informó que su red de distribución no experimentó daños en la infraestructura, pero que optó por suspender temporalmente el suministro del servicio en los edificios que resultaron dañados y estaban conectados a la red de gas con la finalidad de garantizar la seguridad de los usuarios y de la población en general. En general, se sugirió a los habitantes cerrar la llave del gas el día del sismo para evitar siniestros.

\section{Proceso 3: Cálculo del tiempo inactivo del edificio por efectos de vecindario, $t_{C}$}

En la figura 9 se describe el proceso 3. Como se observa, los efectos de vecindario tienen un gran impacto en la interrupción del negocio debido a que a menudo la reanudación de las actividades empresariales está condicionada por los daños en edificios vecinos y en general por las afectaciones en la zona de ubicación de este dependiendo de las decisiones tomadas por dueños o directivos y las órdenes del gobierno y de la autoridad civil.

Los tiempos de inactividad por las subfuentes correspondientes al Colapso total de un edificio vecino (CTEV), $t_{9}$, Daños severos o colapso parcial de un edificio vecino (DSCPEV), $t_{12}$, Complicaciones en las vías de acceso al inmueble (CVAI), $t_{13}$ y Graves afectaciones en la zona (GAZ), $t_{14}$, se combinan resultando un tiempo total, $t_{C}$, definido como el tiempo inactivo del edificio por efectos de vecindario:

$t_{C}=\max \left(t_{9}, t_{12}, t_{13}, t_{14}\right)$

Como se muestra en la figura 9, el tiempo inactivo por colapso total de un edificio vecino aumenta cuando hay víctimas humanas debido a que la remoción de escombros no puede llevarse a cabo hasta la finalización de las labores de rescate, tal como sucedió con el inmueble del Colegio Enrique Rébsamen (figura 10). En consecuencia, 
$t_{9}=t_{7}+t_{8}$

donde $t_{7} \mathrm{y}_{8}$ son los tiempos inactivos por labores de rescate de víctimas humanas y por trabajos de remoción de escombros de un edificio vecino, respectivamente. En algunos edificios colapsados a causa del sismo del 19S de 2017, además del retiro de materiales se efectuaron algunas actividades de demolición. Se documentó que en ocasiones las actividades de rescate en edificios colapsados demoraron hasta 15 días, lo cual propició una interrupción de los negocios establecidos en los alrededores.

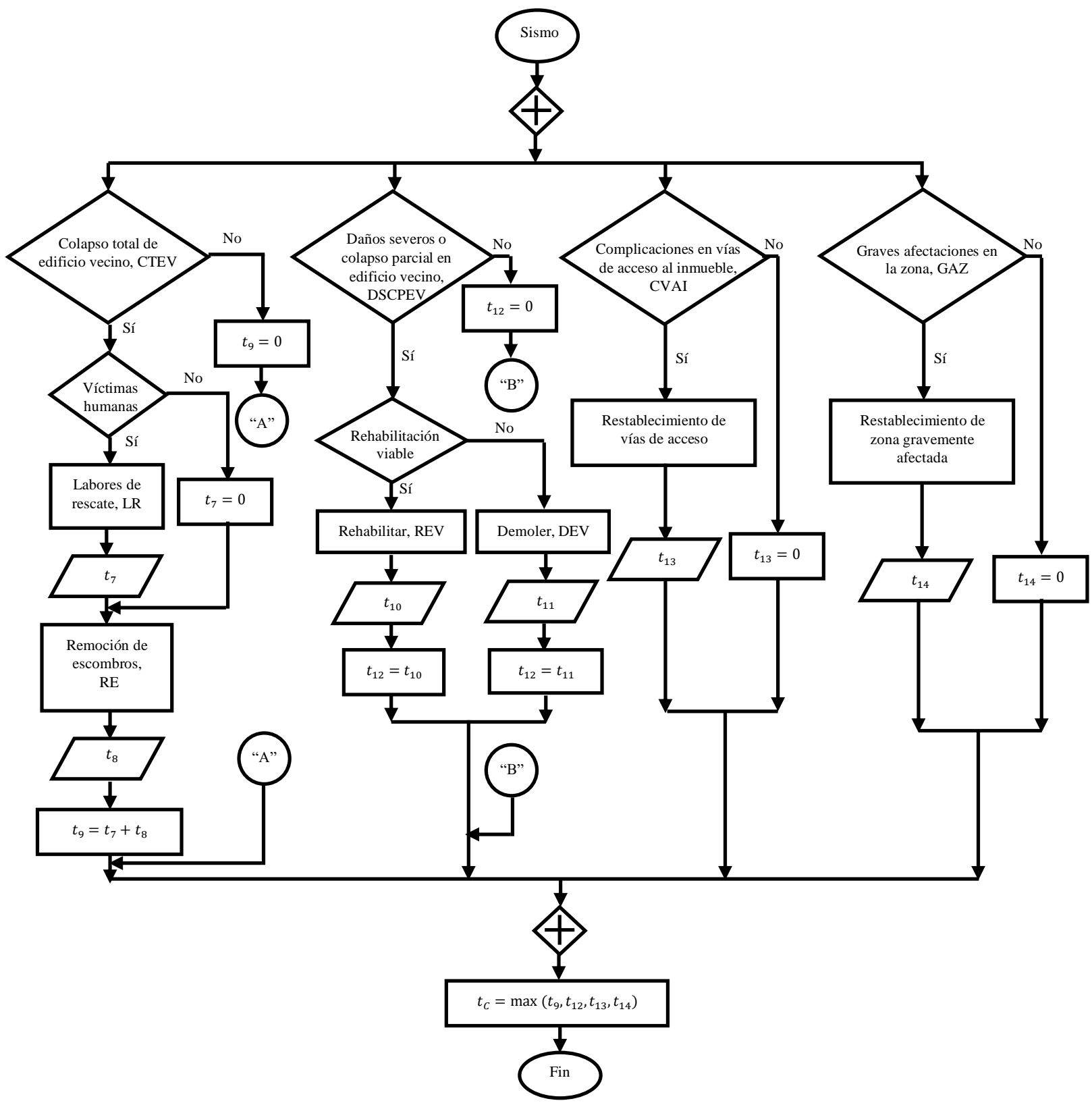

Figura 9. Diagrama de flujo del "Proceso 3: Cálculo del tiempo inactivo del edificio por efectos de vecindario, $t_{C} "$ 


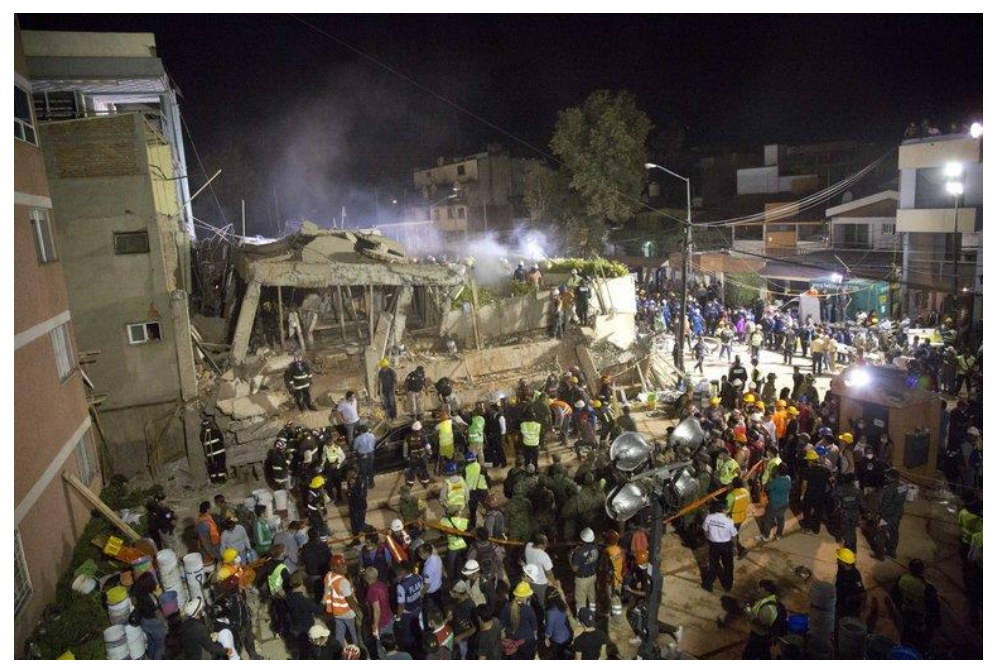

Figura 10. Actividades de rescate tras el colapso del Colegio Enrique Rébsamen. Se identificaron 19 niños y 7 adultos fallecidos. Fuente: Infobae

En el diagrama de flujo mostrado en la figura 9, se considera que $t_{10}$ es el tiempo inactivo del edificio del negocio hasta la rehabilitación de un edificio vecino por daños severos o colapso parcial; si la rehabilitación no es viable, entonces se requiere de su demolición, la cual se observó que en la Ciudad de México se efectuó con maquinaria y trabajos manuales incrementándose el tiempo de interrupción del negocio con respecto a si se hubiera efectuado una demolición con uso de explosivos, la cual se prohibió para evitar afectaciones a inmuebles aledaños y por seguridad de las personas, ya que esta es una de las ciudades más pobladas en el mundo. Asimismo, el tiempo inactivo por demolición de un edificio vecino se define como $t_{11}$ y se considera que el negocio queda paralizado totalmente desde el día de la ocurrencia del sismo hasta la culminación del retiro de escombros del edificio aledaño demolido, es decir, durante las siguientes etapas que se observaron:

- Estudios previos a los trabajos de demolición

- Elaboración y emisión de dictamen de demolición

- Procesos administrativos

- Trabajos de preparación y protección

- $\quad$ Retiro de contenidos de la edificación

- Derribo, fragmentación o desmontaje de la edificación

- $\quad$ Retiro de los materiales derribados

En la tabla 5 se muestra el tiempo aproximado de demolición y el tiempo transcurrido desde la ocurrencia del sismo del 19S de 2017 hasta el retiro total de escombros de tres edificaciones que resultaron con daños severos en la Ciudad de México, las cuales se muestran en la figura 11. La demolición del edificio recargado en un edificio contiguo se retardó varios meses debido a juicios de amparo promovidos por los propietarios del edificio vecino afectado. Asimismo, los trabajos de demolición para un edificio de 16 niveles se llevaron a cabo en aproximadamente tres meses, sin embargo, transcurrió alrededor de un año y tres meses desde el día del sismo hasta el retiro de los materiales de derribo.

Algunos negocios contiguos a los edificios severamente dañados continuaron con sus actividades hasta que iniciaron los trabajos de demolición e incluso durante estos, no obstante, los dueños indicaron que sufrieron una notable disminución en las ventas por la desconfianza de los clientes. 
Tiempo de interrupción de negocios en la Ciudad de México por daños directos y efectos indirectos en edificios a causa del sismo del 19S de 2017

Tabla 5. Tiempo aproximado de demolición y tiempo transcurrido desde la catástrofe hasta la culminación de retiro de escombros para algunos edificios de la CDMX dañados por el sismo del 19S de 2017

\begin{tabular}{|c|c|c|c|c|}
\hline Descripción del edificio & Daños observados & Tipo de demolición & $\begin{array}{l}\text { Tiempo } \\
\text { aproximado de } \\
\text { los trabajos de } \\
\text { demolición }\end{array}$ & $\begin{array}{c}\text { Tiempo aproximado } \\
\text { transcurrido desde el } \\
\text { sismo hasta el retiro } \\
\text { total de escombros }\end{array}$ \\
\hline $\begin{array}{l}\text { Edificación de centro de } \\
\text { atención telefónica de concreto } \\
\text { reforzado de } 3960 \text { metros } \\
\text { cuadrados, con cuatro niveles y } \\
\text { cuartos de azotea. }\end{array}$ & $\begin{array}{l}\text { Daños severos en varias } \\
\text { columnas que pusieron en } \\
\text { peligro la estabilidad } \\
\text { global de la estructura. }\end{array}$ & $\begin{array}{l}\text { Método mixto que consistió en } \\
\text { trabajos manuales que } \\
\text { requirieron de alrededor de } 15 \\
\text { trabajadores y en uso de } \\
\text { maquinaria. }\end{array}$ & 50 días & 6 meses \\
\hline $\begin{array}{c}\text { Edificio de } 11 \text { niveles: sótano, } \\
\text { planta baja, } 24 \text { departamentos } \\
\text { en } 8 \text { pisos y azotea con cuartos } \\
\text { de servicio y cuarto de } \\
\text { máquinas. }\end{array}$ & $\begin{array}{l}\text { Daños severos en } \\
\text { columnas, trabes y losas, y } \\
\text { gran inclinación del } \\
\text { edificio recargándose en un } \\
\text { edificio vecino. }\end{array}$ & $\begin{array}{l}\text { Los trabajos de demolición se } \\
\text { llevaron a cabo con } 50 \\
\text { trabajadores. Los siete niveles } \\
\text { superiores se demolieron } \\
\text { manualmente y luego se } \\
\text { empleó retroexcavadora. }\end{array}$ & 75 días & 9 meses \\
\hline $\begin{array}{c}\text { Edificio de } 16 \text { niveles con } 56 \\
\text { departamentos y ocho locales } \\
\text { comerciales. }\end{array}$ & $\begin{array}{l}\text { Daño estructural en las } \\
\text { columnas de la planta baja } \\
\text { quedando expuestas las } \\
\text { barras de refuerzo de } \\
\text { acero, las cuales fallaron } \\
\text { por compresión. Aberturas } \\
\text { de hasta } 30 \mathrm{~cm} \text { en las } \\
\text { escaleras. El edificio sufrió } \\
\text { deformaciones excesivas } \\
\text { quedando en riesgo } \\
\text { inminente de colapso. }\end{array}$ & $\begin{array}{l}\text { Los trabajos de demolición se } \\
\text { realizaron con una cuadrilla de } \\
40 \text { demoledores en conjunto } \\
\text { con una grúa de } 120 \text { toneladas } \\
\text { y dos retroexcavadoras. }\end{array}$ & 3 meses & 1 año y 3 meses \\
\hline
\end{tabular}

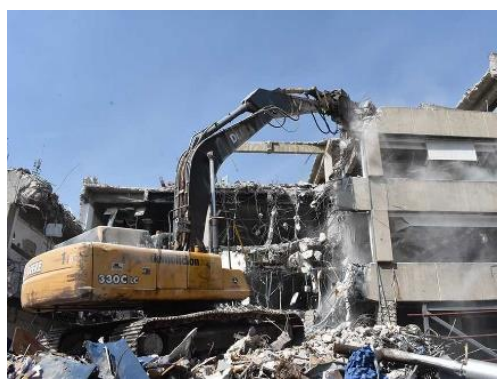

A)

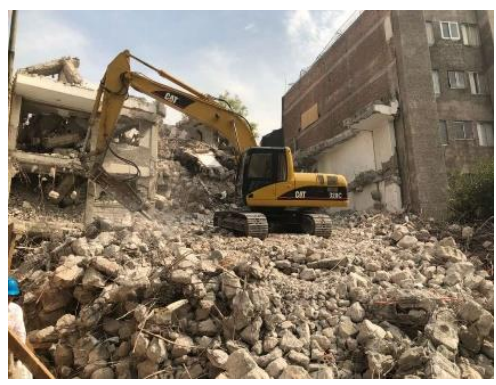

B)

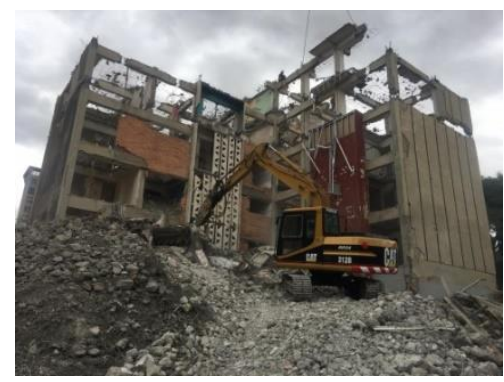

C)

Figura 11. Demolición de edificios dañados severamente ubicados en: A) Puebla 277, colonia Roma Norte, alcaldía Cuauhtémoc. Fuente: Excelsior, B) Paseo del Río 10, colonia Paseos de Taxqueña. Fuente: Heraldo de México, C) Calle Dr. Lucio 102, colonia Doctores. Fuente: Excelsior 
Para efectos de este trabajo, las complicaciones en las vías de acceso al inmueble se definen como el congestionamiento ante la emergencia del desastre y los daños (incluyendo colapsos) tanto de carreteras como de puentes, lo cual dificulta o impide la asistencia del personal y de los clientes o los consumidores a las instalaciones del negocio.

El sismo del 19S también dañó la infraestructura vial. De acuerdo con Caminos y Puentes Federales de Ingresos y Servicios Conexos (CAPUFE) y la Policía Federal, dentro de las afectaciones que se propiciaron están el colapso de un puente de la autopista México-Acapulco, tramo CuernavacaChilpancingo 109+000, la aparición de grietas de aproximadamente $50 \mathrm{~cm}$ y un hundimiento de un metro en el kilómetro 25 de la carretera del Estado de México en dirección a Nicolas Romero con Santa Ana Jilotzingo y agrietamientos desde la calle Panorama hasta la calle Cocoxochitl, deformación del pavimento y desprendimiento del material en los muros de contención en la carretera Xochimilco-Tulyehualco (figura 12). Aunque no se cuenta con información sobre el tiempo de reparación de los primeros dos casos citados, está documentado que la carretera Xochimilco-Tulyehualco estuvo cerrada alrededor de 565 días, debido a que se requirió de reconstruir $674 \mathrm{~m}$ de muros de contención, recuperar $3100 \mathrm{~m}^{2}$ de áreas verdes, así como de restaurar la carpeta asfáltica en $11200 \mathrm{~m}^{2}$, rehabilitar $570 \mathrm{~m}^{2}$ de banquetas y $313 \mathrm{~m}$ de guarniciones, renovar los señalamientos viales e instalar 10 postes de luz ahorradores de energía en las vialidades aledañas.

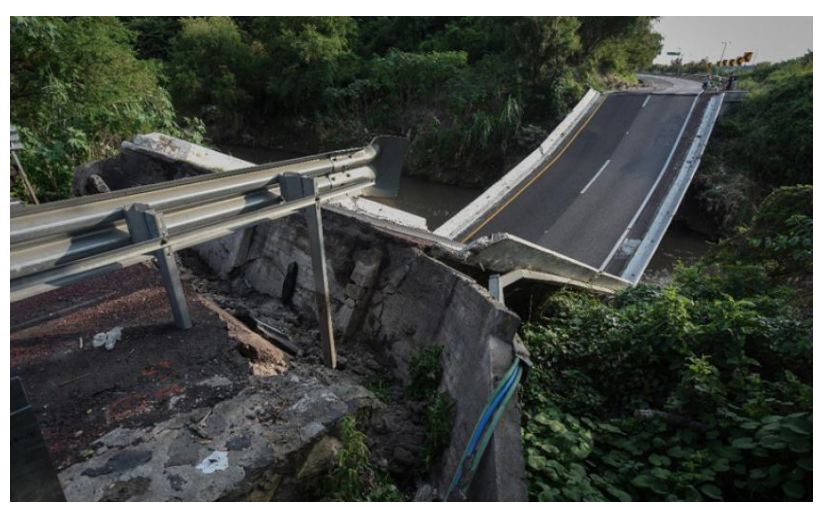

A)

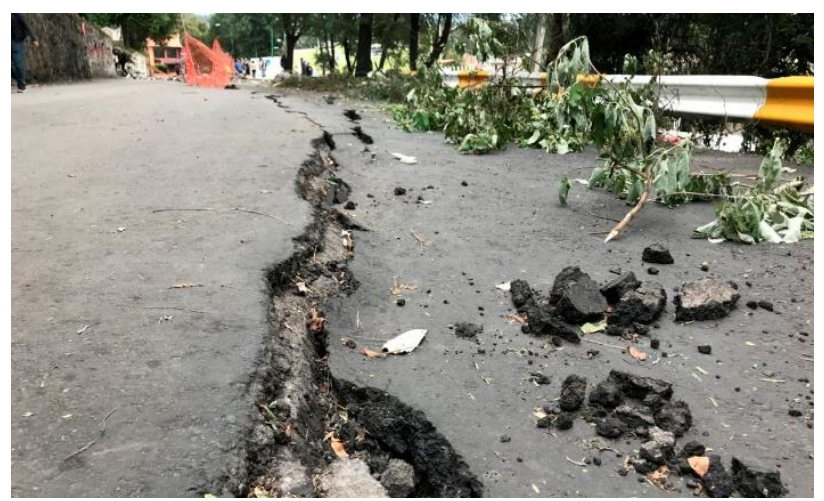

B)

Figura 12. Daños en la infraestructura vial: A) Colapso de un puente en la autopista México-Acapulco. Fuente: El Universal. Créditos: Policía Federal y B) Agrietamiento en la carretera XochimilcoTulyehualco. Fuente: Quadratín México

Debido a la evidencia fehaciente relativa a la población afectada, considerando personas lesionadas, fallecidas y evacuadas, pérdidas materiales y daños a los servicios vitales, edificios, sistemas estratégicos y medio ambiente, el gobierno de la CDMX realizó una declaratoria de emergencia un día después del sismo ocurrido el 19S de 2017 con motivo de este evento catastrófico, en la que con base en el artículo 9 suspendió todos los eventos, concentraciones y espectáculos masivos en espacios públicos en la Ciudad de México durante la vigencia de la declaratoria citada (Gobierno de la Ciudad de México (A), 2017). El 29 de septiembre emitió un decreto en el cual dio por terminada la suspensión establecida en dicho artículo (Gobierno de la Ciudad de México (B), 2017), de modo que a partir de ese día inmuebles como auditorios, estadios, foros, cines, teatros, establecimientos mercantiles dedicados a espectáculos públicos y centros culturales reanudaron sus actividades paulatinamente al cumplir con la normatividad en materia de Protección Civil, Espectáculos Públicos y Seguridad Estructural. Se registraron algunas excepciones de negocios de este tipo que pudieron operar nuevamente con antelación a la fecha citada al obtener un dictamen de seguridad estructural favorable (sin riesgo), por ejemplo, el Papalote Museo del Niño y el Museo de Arte Popular efectuaron su reapertura el 25 y el 27 de septiembre de 2017, mientras que algunos 
recintos permanecieron abiertos durante todo este periodo únicamente para servir como albergues y centros de acopio, tal fue el caso de la Casa Refugio Citlaltépetl.

Además, el 21 de septiembre de 2017 el gobierno de la CDMX declaró zona de desastre las áreas de la Ciudad de México afectadas por el sismo (Gobierno de la Ciudad de México (C), 2017). Se observó que la reapertura de muchos negocios se llevó a cabo tras un restablecimiento parcial y no total de la zona gravemente afectada.

\section{Proceso 4: Cálculo del tiempo inactivo por daños en los componentes del edificio, $t_{E}$}

En el proceso 4 (figura 13) el edificio pierde su operatividad debido a daños en sus componentes. El valor máximo de los tiempos de inactividad por las subfuentes Daño en elementos estructurales (DEE), Daño en elementos no estructurales (DENE) y Daño en contenidos (DC), $t_{15}, t_{16}$ y $t_{17}$ respectivamente, da como resultado el tiempo inactivo por daños físicos en el edificio, $t_{E}$.

$t_{E}=\max \left(t_{15}, t_{16}, t_{17}\right)$

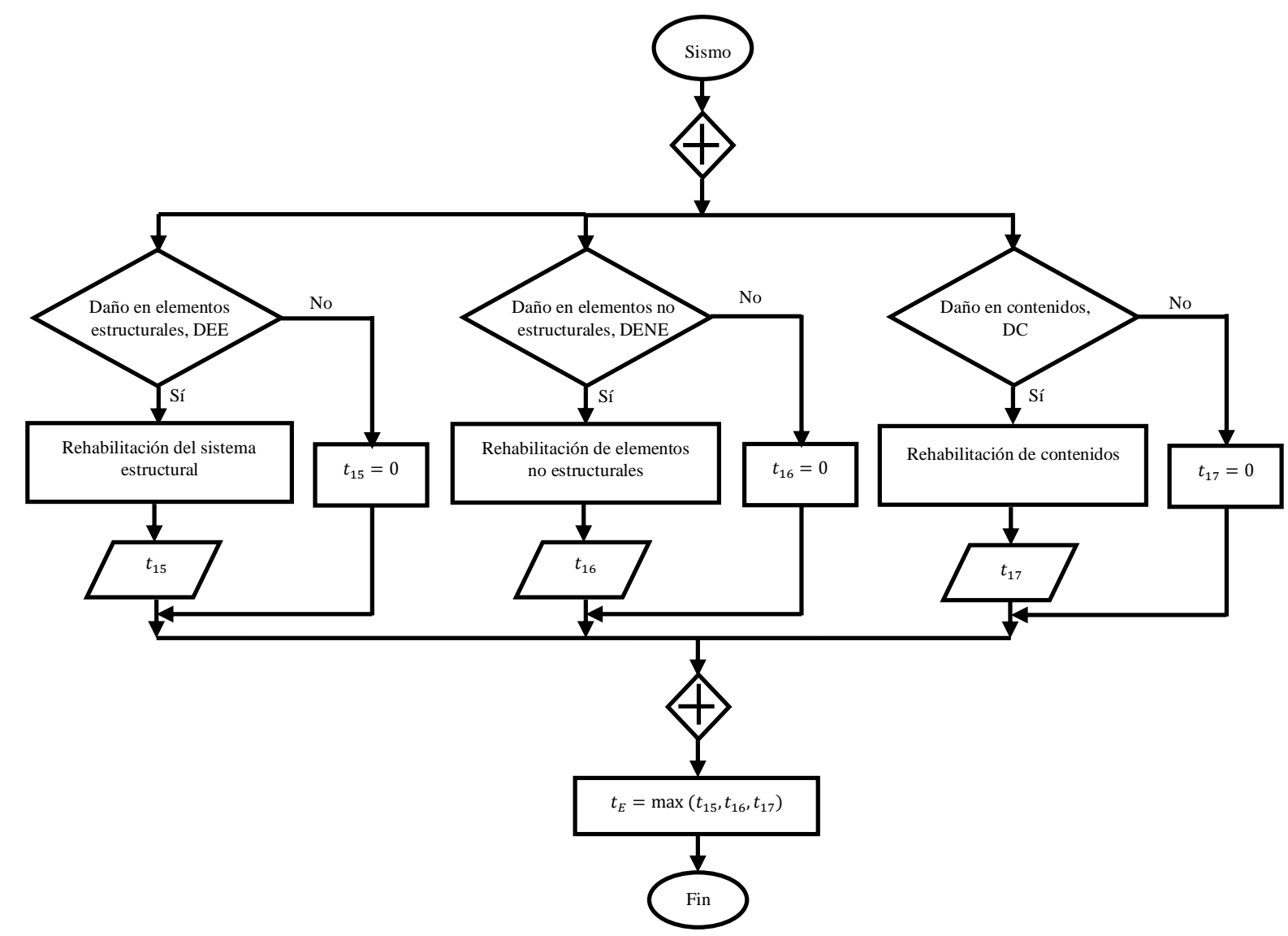

Figura 13. Diagrama de flujo del "Proceso 4: Cálculo del tiempo inactivo por daños físicos en el edificio, $t_{E} "$.

Aunque los daños en los elementos no estructurales (muros divisorios, ventanas, puertas, plafones, entre otros) no ponen en peligro la estabilidad global de la edificación, se deben rehabilitar a la brevedad 
para recuperar la funcionalidad del inmueble, ya que pueden poner en riesgo la integridad del personal y de los clientes, además de que generan desconfianza en estos, sobre todo en aquellos negocios en los que se está en contacto directo. Algo análogo ocurre con el daño de contenidos tales como maquinaria, mobiliario, equipos y stocks con el problema adicional de que estos pueden impedir totalmente el desarrollo de actividades empresariales específicas, sin embargo, el tiempo de interrupción se puede minimizar si el negocio cuenta con activos tangibles de repuesto. Pese a que los contenidos no se dañen al deslizarse o volcarse por el sismo, la unidad económica puede experimentar una breve interrupción por el reacomodo de estos.

Tras el sismo del 19S del 2017, se observó que los edificios que resultaron con daños en los elementos estructurales o no estructurales quedaron inactivos durante todas las siguientes etapas o en la mayoría de estas:

- Obtención de recursos financieros por parte de los dueños o directivos.

- Evaluación de la seguridad de acuerdo con la legislación vigente.

- Solicitud y elaboración de presupuestos del costo total de la rehabilitación (mano de obra y materiales).

- Selección definitiva del grado de intervención (reparación, reforzamiento, reestructuración, entre otros), de las técnicas de rehabilitación y de quienes llevaron a cabo los trabajos de campo y gabinete

- con base en la decisión del propietario del edificio o de las autoridades competentes y las recomendaciones de ingenieros o expertos en construcción.

- Elaboración del proyecto de rehabilitación con base en la normativa de construcción vigente (RCDF, 2017), incluyendo trabajos de campo adicionales a los efectuados en otros niveles de evaluación, cálculos estructurales, elaboración de planos y memorias de cálculo definitivas.

- Permisos gubernamentales.

- Construcción de la rehabilitación estructural o no estructural.

En la evaluación detallada de daños se llevó a cabo un levantamiento más minucioso de los daños en las edificaciones (ReNE, 2018) poniéndose énfasis en los daños estructurales máximos observables (mecanismo y características) con el objetivo de proponer, en ocasiones de manera previa o provisional, el tipo y las técnicas de rehabilitación, y también se identificaron las afectaciones en otros elementos como tanques, lámparas, balcones, escaleras, entre otros (tabla 6). Los inmuebles quedaron inactivos durante la solicitud del servicio y la realización de los trabajos de campo y gabinete.

En ocasiones se requirió de una evaluación estructural formal aún más detallada junto con un proyecto de rehabilitación (ReNE, 2018) llevados a cabo por un despacho de Ingeniería Estructural o una empresa especializada en rehabilitación estructural (tabla 6). En edificios con un nivel de daño global estructural severo o con colapso parcial se determinó con base en un análisis costo-beneficio si la rehabilitación estructural era viable o si estos debían demolerse.

Aunque algunas investigaciones se han enfocado en el análisis e interpretación de los daños y en la evaluación del comportamiento de sistemas estructurales de distintos edificios por el sismo del 19S de 2017 (Buendía y Reinoso, 2019; Rodríguez, 2019; Tapia y García, 2019; Pujol y Rodríguez; 2019) e inclusive en la rehabilitación de estos (Ruiz et al., 2019), no se dispone de un inventario de edificios en el que se relacionen los daños directos en estos con el tiempo de ejecución de obras de rehabilitación ni con el tiempo total en el que perdieron su funcionalidad. 
Tiempo de interrupción de negocios en la Ciudad de México por daños directos y efectos indirectos en edificios a causa del sismo del 19S de 2017

Tabla 6. Niveles minuciosos de evaluación estructural acorde con el sismo del 19S de 2017 en México

\begin{tabular}{cccc}
\hline Nivel de Evaluación & Personal que efectuó la evaluación & $\begin{array}{c}\text { Período de realización } \\
\text { aproximado }\end{array}$ & $\begin{array}{c}\text { Duración promedio } \\
\text { de los trabajos de } \\
\text { campo }\end{array}$ \\
\hline Evaluación detallada & DRO y CSE & $\begin{array}{c}\text { Durante las primeras } \\
\text { tres semanas posteriores } \\
\text { a la primera semana de } \\
\text { haber ocurrido el sismo }\end{array}$ & {$[1 \mathrm{~h}, 4 \mathrm{~h}]$} \\
$\begin{array}{c}\text { Evaluación estructural } \\
\text { formal y diseño del } \\
\text { proyecto de } \\
\text { rehabilitación }\end{array}$ & $\begin{array}{c}\text { Despacho de Ingeniería Estructural o empresa } \\
\text { especializada en rehabilitación estructural }\end{array}$ & $\begin{array}{c}\text { Durimeros } \\
\text { seis meses posteriores } \\
\text { al primer mes de haber } \\
\text { ocurrido el sismo }\end{array}$ & $\begin{array}{c}\text { Hasta varias } \\
\text { semanas }\end{array}$ \\
\hline
\end{tabular}

Sin embargo, con base en algunos casos documentados, se identificó que el tiempo inactivo de los edificios fue muy variable, ya que ciertos negocios cerraron únicamente por algunos días debido a daños leves localizados o generalizados en el sistema estructural o por daños menores en los elementos no estructurales en los inmuebles, por ejemplo, el hotel Holiday Inn Coyoacán dejó de operar 22 días, por el contrario, determinadas unidades económicas perdieron su operatividad por un tiempo muy prolongado a causa de daños severos o colapsos parciales o totales en sus instalaciones, por ejemplo, a un año de haber ocurrido el sismo del 19S de 2017, el centro comercial Galerías Coapa continuaba cerrado, aunque tenía contemplado reanudar sus actividades el 31 de octubre de 2018, la unidad Suburbia Villa Coapa se encontraba realizando trabajos de reconstrucción y tenía previsto efectuar su reapertura a mediados del 2019, mientras que la tienda Soriana de Taxqueña no se había logrado recuperar del colapso y no tenía planeada una reconstrucción (figura 14).

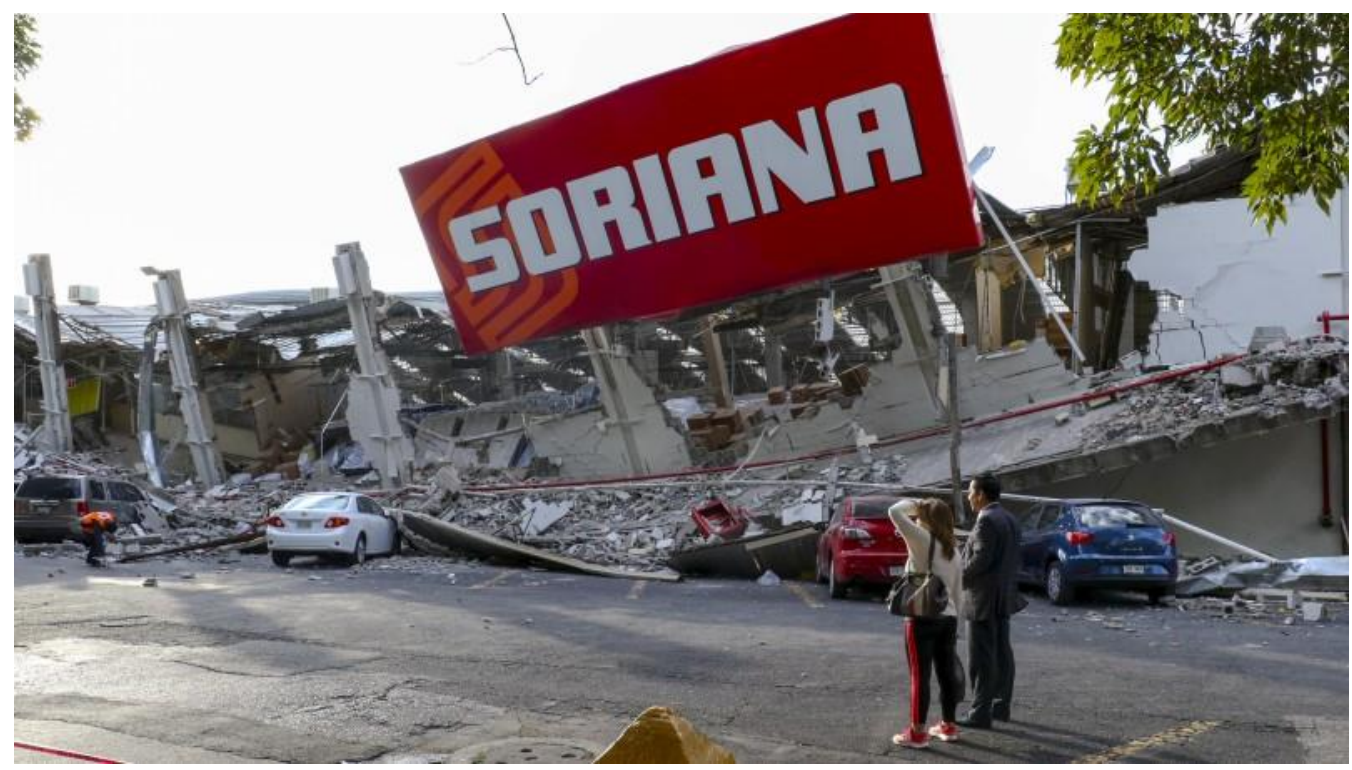

Figura 14. Colapso de la tienda Soriana Taxqueña. Fuente: Expansión. Créditos: Saúl López / Cuartoscuro

Además, se identificó otra gran variedad de factores que influyeron en el tiempo de recuperación de la funcionalidad de los edificios, los cuales se enlistan a continuación:

- El tiempo de rehabilitación varió significativamente para negocios que ostentaban un seguro de daños para los activos tangibles, habiendo sido de interés para el asegurado la liquidación de los reclamos del seguro a la mayor brevedad con la finalidad de reducir las pérdidas por interrupción de negocio. De acuerdo con la Asociación Mexicana de Instituciones de Seguros, un año después de los sismos 
del 7S y 19S de 2017, las compañías aseguradoras habían cubierto $82 \%$ de las 73,124 solicitudes que se presentaron para el pago de los daños que se registraron en casa-habitación, comercios, oficinas, inmuebles gubernamentales y hospitales. Las pérdidas en estos inmuebles fueron de alrededor de 30,100 millones de pesos, de las cuales el sector asegurador había efectuado la cobertura de aproximadamente el $60 \%$.

- En edificios dañados producto de un choque con un edificio vecino, el tiempo de rehabilitación se retrasó notablemente debido a los acuerdos entre los dueños de los inmuebles afectados o por los procesos legales.

- Los recursos financieros otorgados por el gobierno fueron fundamentales para la reconstrucción.

- El tiempo de ejecución de las actividades de rehabilitación estructural estuvo en función de las características del sistema estructural, de la severidad, magnitud y propiedades de los daños, así como de la cantidad de trabajadores que ejecutaron las actividades correspondientes.

- El comienzo de la construcción de la rehabilitación también se retardo debido a que, ante el número elevado de edificios dañados, el costo de la mano de obra y de los materiales constructivos aumentó considerablemente. Este fenómeno conocido como "demand surge" no se aborda con detalle en este trabajo.

Las decisiones de los dueños también fueron determinantes en el tiempo de interrupción de los negocios. Se registraron casos en los que, debido a que los daños en los elementos estructurales y no estructurales no ponían en peligro la seguridad del personal y de los clientes, se continuaron con las operaciones en el negocio tras la inspección post-sísmica, de modo que la rehabilitación se llevó a cabo de manera simultánea a estas, en días inhábiles o incluso nunca se efectuó. Por ejemplo, el hotel Filadelfia que está ubicado frente al World Trade Center de la CDMX ofreció sus servicios nuevamente un día después del sismo una vez que se efectuó la evaluación de la seguridad del inmueble en el que sólo se registraron daños menores, los cuales fueron reparados en su totalidad a una semana de la ocurrencia del evento natural simultáneamente al desarrollo de las actividades empresariales.

\section{CÁLCULO DEL TIEMPO TOTAL INACTIVO DE UN EDIFICIO PARA UN NEGOCIO HIPOTÉTICO}

Los conceptos anteriores se ejemplifican con un negocio hipotético de la Ciudad de México establecido en una edificación de dos niveles cuyo sistema estructural es de mampostería confinada para determinar el tiempo de inactividad aproximado del inmueble producto de un sismo hipotético. Se considera que este evento destructivo ocurre al inicio de la jornada laboral, siendo necesario llevar a cabo los protocolos de seguridad iniciales, y que además produce un corte de luz debido a daños en postes y cables en la infraestructura de energía eléctrica y genera daños muy severos en un muro de carga de $10 \mathrm{~m}^{2}$ de la planta alta con unidades de mampostería de tipo block macizo de $12 \times 20 \times 40$ con aparejo de panderete (colocadas en todas las hiladas con la cara de mayor superficie a la vista). La relación entre la intensidad sísmica y las fuentes de interrupción se encuentra fuera del alcance de este trabajo.

Aunque existen varias escalas para clasificar el grado de daño por sismo de muros de mampostería confinada, en este trabajo se emplea el criterio propuesto por Rodríguez y Castrillón (1995), puesto que es el que recomienda Alcocer (2019) debido a que las NTC-DCEM (2017) también consideran cinco niveles de daño. Como el muro presenta daños muy severos, de acuerdo con el grado $\mathrm{V}$ del criterio utilizado, se observan grietas diagonales con un ancho de $7 \mathrm{~mm}$ que pasan a través de una gran cantidad de unidades de mampostería del muro y se identifica un agrietamiento en las zonas adyacentes a las conexiones dala-castillo del muro, el cual se extiende en los elementos de confinamiento de concreto (grietas de $2 \mathrm{~mm}$ ), además de una falla del refuerzo longitudinal y transversal de los elementos de confinamiento. 
Con la finalidad de ilustrar la importancia que tiene el hecho de que el negocio disponga de liquidez y la influencia de la participación de los Ingenieros Estructuristas para minimizar el tiempo de interrupción del negocio, se asume que el propietario del edificio cuenta con los recursos financieros necesarios para contratar los servicios de Ingenieros para la realización de la inspección post-sísmica y la evaluación detallada de daños, así como para la rehabilitación estructural de la edificación, y que hay una buena disponibilidad de estos profesionistas para realizar los correspondientes trabajos de campo y de gabinete.

Además, se considera que existen suficientes recursos, tanto de materiales constructivos como humanos, para la ejecución de obras de reparación estructural. También se supone que la edificación se clasifica como de "Vulnerabilidad sísmica baja" de acuerdo con la investigación de campo en la que se evalúa cuidadosamente cada detalle del inmueble (aspectos geométricos, aspectos constructivos, aspectos estructurales, cimentación, suelo y entornos) utilizándose el método simplificado publicado por el CENAPRED (n.d.), el cual consiste en una adaptación del método propuesto por la Asociación Colombiana de Ingeniería Sísmica (AIS,2001) considerando las características de las construcciones y sismicidad en México. Además, el grado de daño global estructural del edificio de mampostería confinada se clasifica como "severo A" de acuerdo con la escala propuesta por Ortiz y Reinoso (2017). Por lo tanto, para reparar la estructura se emplean las técnicas de reemplazamiento del muro y de reconstrucción de los elementos de confinamiento incluyendo el reemplazo de las barras de refuerzo. La elaboración del proyecto de rehabilitación es llevada a cabo por un Ingeniero Estructurista local, mientras que las obras se llevan a cabo por una cuadrilla de la zona conformada por un oficial albañil un peón.

El tiempo inactivo del edificio, $t_{T I E}$, puede calcularse combinando las ecuaciones 3 y 4 . Debido a que no hay efectos de vecindario que propicien una interrupción del negocio, $t_{C}=0$. Por consiguiente:

$t_{T I E}=\max \left(t_{A}, t_{B}, t_{E}\right)$

donde $t_{A}, t_{B}$ y $t_{E}$ son los tiempos inactivos por Protocolos de seguridad iniciales (PSI), Suspensión de servicios públicos de suministro (SSPS) y Daños en los componentes del edificio (DCE).

De la ecuación 5 se conoce que el tiempo inactivo por PSI es $t_{A}=\max \left(t_{1}, t_{2}\right)$. Además, como únicamente se suspende el servicio público de energía eléctrica y sólo hay daños en el sistema estructural del edificio, los tiempos inactivos por SSPS y DCE son, de forma respectiva, $t_{B}=t_{3}$ y $t_{E}=t_{15}$. Al reemplazar estos tiempos en la ecuación 10, resulta:

$t_{T I E}=\max \left(t_{1}, t_{2}, t_{3}, t_{15}\right)$

donde $t_{1}, t_{2}, t_{3}$ y $t_{15}$ son los tiempos de inactividad medidos desde la ocurrencia del sismo por las subfuentes Ocurrencia del sismo en horario laboral (OSHL), Inspección post-sísmica del edificio (IPE), Suspensión del suministro de energía eléctrica (SSEE) y Daño en elementos estructurales (DEE), respectivamente.

En la figura 15 se muestra el diagrama de Gantt con las actividades desarrolladas durante el tiempo de cierre del negocio y en la figura 16 se muestra el diagrama de Gantt del tiempo de ejecución de las actividades de rehabilitación estructural del edificio, el cual se ha determinado con base en rendimientos obtenidos a partir de aplicar entrevistas a expertos en construcción de la CDMX. 


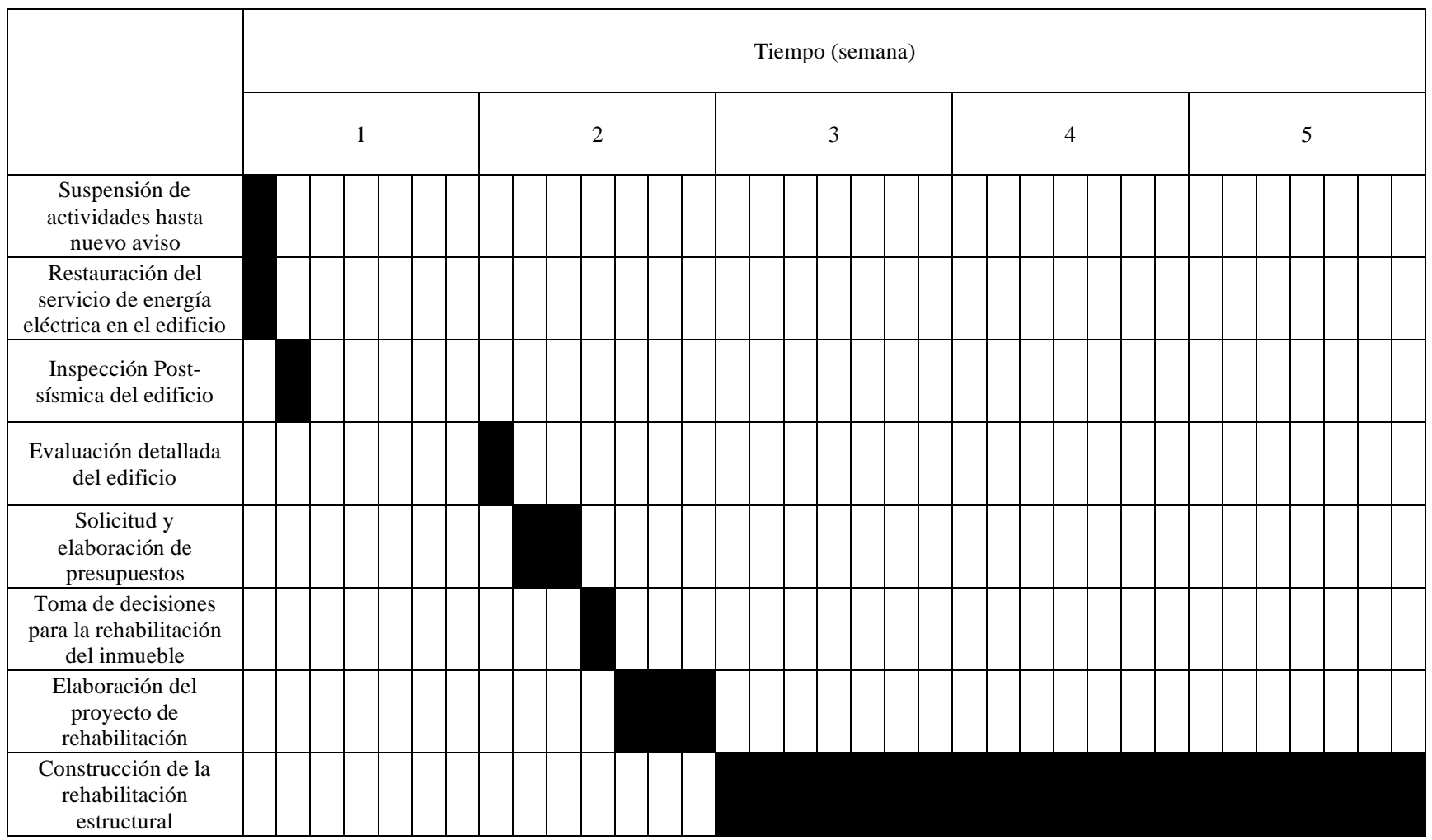

Figura 15. Tiempo total inactivo del edificio o de cierre del negocio

Como el sismo ocurre dentro de la jornada de trabajo, el dueño del negocio se ve forzado a suspender las actividades empresariales por el resto del día y hasta nuevo aviso, además, en ese mismo día se restaura la energía eléctrica, de modo que los tiempos de inactividad por OSHL y SSEE son $t_{1}=t_{3}=1 d$. Puesto que la inspección post-sísmica del edificio se realiza al día siguiente de haber ocurrido el sismo, el tiempo de inactividad por IPE es $t_{2}=2 d$. En el dictamen se establece que el inmueble se clasifica como "Edificación o área insegura / Riesgo alto", por consiguiente, este no se puede ocupar temporalmente. Por otra parte, el tiempo de inactividad por DEE es $t_{15}=35 d$, debido a que el tiempo asociado a los factores que impiden el inicio de las reparaciones es de dos semanas, ya que además de lo expuesto para $t_{1}, t_{2}$ y $t_{3}$, se requiere de una evaluación detallada del edificio, una elaboración de presupuestos, la toma de decisiones y la elaboración del proyecto de rehabilitación, mientras que el tiempo asociado a la ejecución de las obras de reparación es de 3 semanas (figura 16). Al reemplazar los valores de los tiempos correspondientes en la ecuación 11 resulta:

$t_{T I E}=\max (1 d, 2 d, 1 d, 35 d)=35 d$

Por lo tanto, el tiempo de cierre del negocio es de 35 bajo la condición de que la reapertura de este se lleve a cabo al día siguiente de la culminación de las reparaciones estructurales. Es muy probable que la unidad económica experimente algunos trastornos como pérdida de clientes, por lo que le tomaría un tiempo considerable recuperar la productividad. Finalmente, la pérdida por el tiempo total de interrupción del negocio, que está en función de las características de este, es determinada por el respectivo personal con base en la información sobre los ingresos y gastos a través de un estado de resultados. 
Tiempo de interrupción de negocios en la Ciudad de México por daños directos y efectos indirectos en edificios a causa del sismo del 19S de 2017

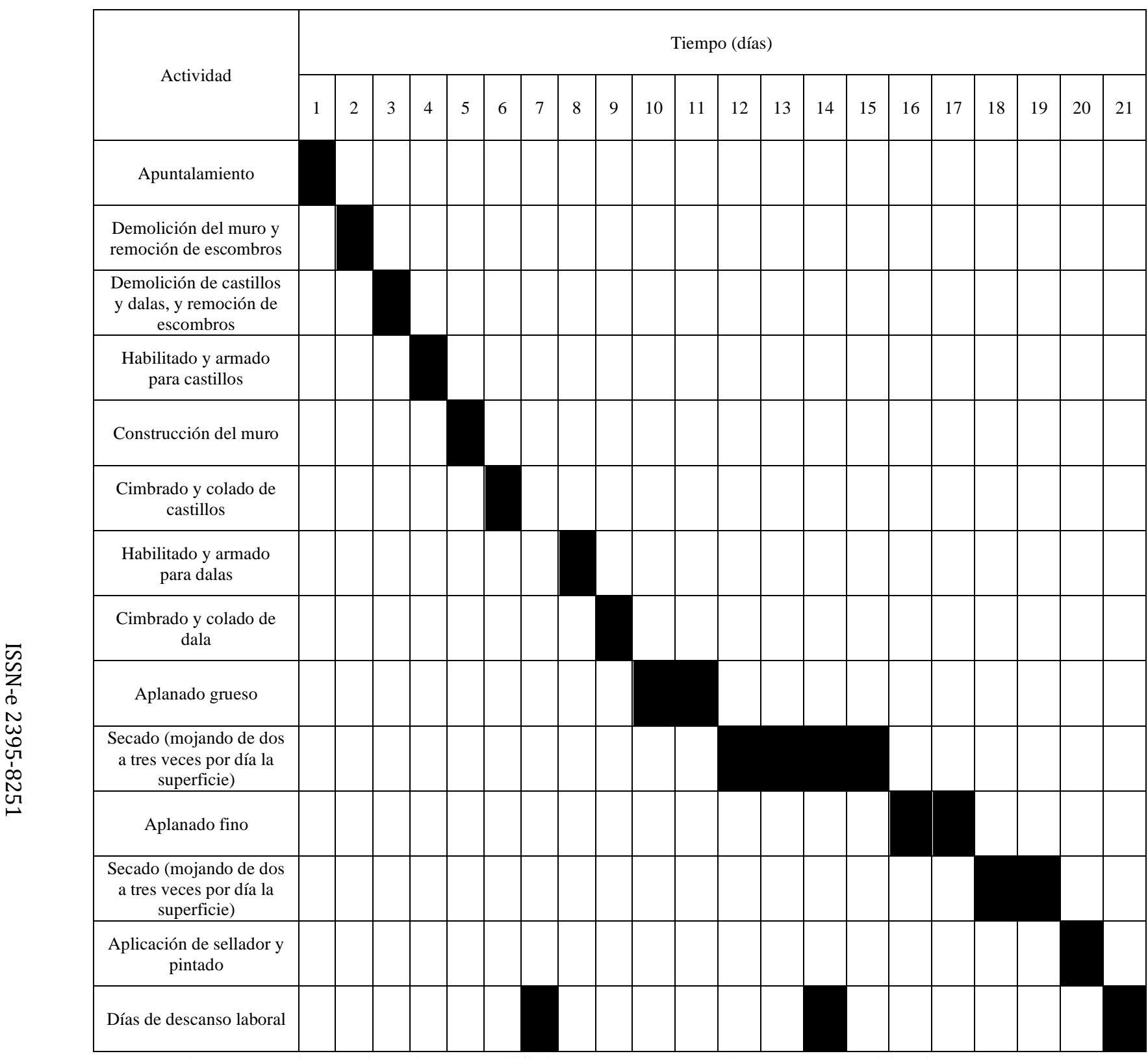

Figura 16. Tiempo inactivo del edificio por la construcción de la rehabilitación estructural

\section{CONCLUSIONES}

El sismo del 19S de 2017 ha sido uno de los más catastróficos en la historia de México, debido a que derivó grandes problemas sociales y económicos, entre ellos, afectaciones a las unidades económicas. Con base en lo sucedido tras este evento, en este trabajo se han identificado las fuentes de interrupción de los negocios de la CDMX, se ha propuesto un modelo para determinar el tiempo inactivo aproximado del edificio y se ha recabado información sobre los daños a las infraestructuras y los tiempos de rehabilitación para la Ciudad de México, entre otros aspectos, con la finalidad de tener valores de referencia para los datos de entrada. Finalmente se han ejemplificado los conceptos con un negocio hipotético. 
Debido a la ocurrencia de este sismo, se observó que una gran cantidad de negocios dejó de operar temporalmente e incluso de forma definitiva por distintas razones. Se documentaron varios casos en los que esto se propició sin que los edificios en los que estaban establecidos sufrieran daños estructurales o no estructurales. Por ejemplo, 25 complejos de la empresa de Cinépolis cerraron alrededor de seis días por la evaluación de la seguridad de los inmuebles, mientras que dos días después del sismo 267 tiendas de la empresa Oxxo de las 300 que habían paralizado sus actividades en la Ciudad de México efectuaron su reapertura tras la restauración de la energía eléctrica.

Aunque la participación de todos los individuos es fundamental para lograr la recuperación social y económica luego de un desastre, en esta investigación se concluye que la contribución de los Ingenieros Civiles o Estructuristas y Arquitectos es trascendental para minimizar el tiempo de interrupción de los negocios e inclusive evitar el fracaso de estos y, por lo tanto, disminuir las pérdidas por sismo. Esta contribución de estos profesionistas estriba no sólo en las investigaciones que han realizado para mejorar el comportamiento de los edificios ante sismos, garantizando la seguridad de los ocupantes y limitando los daños en los edificios para que los negocios operen lo más pronto posible tras un evento muy fuerte, sino que también, como se evidenció tras el sismo del 19S de 2017, radica en su colaboración para la evaluación de la seguridad de los edificios y la rehabilitación de las distintas infraestructuras.

Para el caso hipotético abordado en este trabajo sobre un negocio establecido en un edificio de mampostería confinada, se obtuvo que este podría tener una paralización de alrededor de cinco semanas principalmente por algunos daños severos en la planta alta. Se ha supuesto que existe una buena disponibilidad de los Ingenieros para llevar a cabo la inspección post-sísmica, la evaluación detallada, la elaboración del proyecto de rehabilitación del edificio y la supervisión de la ejecución de obras correspondiente, ya que de lo contrario el tiempo de cierre del negocio calculado hubiera sido considerablemente mayor.

\section{RECOMENDACIONES}

Se reconoce que la mayoría de los tiempos de interrupción de los negocios reportados en este estudio no se relacionan directamente con parámetros cuantificables de peligro sísmico y vulnerabilidad de las estructuras, normalmente empleados en ingeniería sísmica. No obstante, dado que no existe mucha información en la literatura sobre el tiempo en el que las unidades económicas paralizan sus actividades por daños a causa de sismos destructivos, se considera que este estudio puede servir al menos como un referente general. En futuras investigaciones al respecto, sugerimos a Ingenieros Estructuristas relacionar tiempos de interrupción de negocios con índices de daño de edificios para distintas intensidades sísmicas.

Finalmente, recomendamos a los dueños o directivos de los negocios considerar los efectos sísmicos directos e indirectos en los edificios expuestos en este trabajo para poder estructurar de mejor manera los planes de continuidad y de contingencia de sus unidades económicas. Dentro de las acciones resilientes, se sugiere disponer de liquidez para la rehabilitación estructural o no estructural del edificio y otros activos tangibles, contratar un seguro de daños directos y un seguro para la interrupción del negocio, contar con opciones alternas para el suministro de servicios esenciales, tales como plantas de emergencia o reservorios de agua potable, y tener el contacto de un Ingeniero Civil que ostente al menos el grado de Maestro en Ingeniería Estructural o que cuente con una certificación en la materia para la realización de la evaluación de la seguridad del edificio. 


\section{AGRADECIMIENTOS}

Agradecemos al Consejo Nacional de Ciencia y Tecnología (CONACYT) por el apoyo económico brindado al primer autor durante la realización de esta investigación, al personal de los negocios de la CDMX afectados por el sismo M7.1 del 19S de 2017 que accedió a ser entrevistado y a los distintos medios de comunicación de México que proporcionaron datos sobre la interrupción de negocios y las subfuentes de interrupción, así como a los maestros de obra y albañiles entrevistados para obtener el tiempo de reparación estructural en el caso hipotético.

\section{REFERENCIAS}

Alcocer, S (2019), Rehabilitación de Estructuras de Mampostería. En SMIE, Edificaciones de mampostería, pp. 281-336. Ciudad de México: LIMUSA.

Alesch, D, L Arendt y J Holly (2009), "Managing for Long-Term Community Recovery in the Aftermath of Disaster". Public Entity Risk Institute.

Asociación Colombiana de Ingeniería Sísmica, AIS. (2001), Manual de construcción, evaluación y rehabilitación sismo-resistente de viviendas de mampostería. Colombia: LA RED.

ATC-13. (1985), "Earthquake damage evaluation for California". Washington D. C, Estados Unidos: Federal Agency Emergency Management, FEMA.

Buendía, L M y E Reinoso (2019), "Análisis de los Daños en Viviendas y Edificios Comerciales Durante la Ocurrencia del Sismo del 19 de Septiembre de 2017". Revista de Ingeniería Sísmica, 19-35. DOI: $\underline{0.18867 / \text { ris. } 101.508}$

CENAPRED (n.d.), Evaluación simplificada de la vulnerabilidad sísmica de viviendas. SEGOB, SINAPROC, CENAPRED.

Chang, S (2016), "Socioeconomic Impacts of Infrastructure Disruptions". Oxford Research Encyclopedia of Natural Hazard. DOI: 10.1093/acrefore/9780199389407.013.66

Chang, S y A Falit-Baiamonte (2002), "Disaster vulnerability of businesses in the 2001 Nisqually earthquake". Environmental Hazards, 59-71. DOI: 10.1016/S1464-2867(03)00007-X

Chang, S y A Lotze (2014), "Infrastructure contribution to business disruption in earthquakes: model and application to North Vancouver, Canada". Tenth U.S. National Conference on Earthquake Engineering: Frontiers of Earthquake Engineering.

Consorcio Evaluación de Riesgos Naturales- América Latina. (n.d.), Tomo I: Metodología de modelación probabilista de riesgos naturales. Informe técnico ERN-CAPRA-t1-5: Vulnerabilidad de edificaciones e infraestructura. Colombia, España y México.

Federal Emergency Management Agency, FEMA. HAZUS®-MH 2.1. (2013, NOVIEMBRE 17), Technical Manual: Earthquake Model. Retrieved from FEMA: http://www.fema.gov/medialibrary/assets/documents/24609?id=5120

Fernandez, E (2016, octubre 19), Lessons From the Tianjin Explosion - Business Interruption and Contingent Business Interruption. Retrieved from Gen Re: http://www.genre.com/knowledge/blog/business-interruption-and-contingent-business-interruptionen.html

Gama, A, H Juárez, y R Arroyo (2012), "Avances recientes en las metodologías para la evaluación estructural de edificaciones típicas". XVIII Congreso Nacional de Ingeniería Estructural. Acapulco, Guerrero: Sociedad Mexicana de Ingeniería Estructural. 
Gobierno de la Ciudad de México (A), (2017), Declaratoria de Emergencia con motivo del fenómeno sísmico ocurrido el diecinueve de septiembre de dos mil diecisiete en la Ciudad de Mexico. Ciudad de México: Gaceta Oficial de la Ciudad de México.

Gobierno de la Ciudad de México (B), (2017), Declaratoria de Desastre con motivo del fenómeno sísmico ocurrido el diecinueve de septiembre de dos mil diecisiete en la Ciudad de Mexico. Ciudad de México: Gaceta Oficial de la Ciudad de México.

Gobierno de la Ciudad de México (C), (2017), Decreto por el cual se da por terminada la suspensión establecida por el artículo 9 de la Declaratoria de Emergencia con motivo del fenómeno sísmico ocurrido el diecinueve de septiembre de dos mil diecisiete en la Ciudad de Mexico. Ciudad de México: Gaceta Oficial de la Ciudad de México.

Haselton, C, A Liel, G Deierlein, B Dean y J Chou (2011), "Seismic Collapse Safety of Reinforced Concrete Buildings: I. Assessment of Ductile Moment Frames". American Society of Civil Engineers Journal of Structural Engineering , 481-491. DOI: 10.1061/(ASCE)ST.1943-541X.0000318

Haselton, C, A Liel, S Lange y G Deierlein (2007), Beam-Column Element Model Calibrated for Predicting Flexural Response Leading to Global Collapse of RC Frame Buildings. Berkeley: Pacific Earthquake Engineering Research Center, University of California.

Instituto Nacional de Estadística y Geografía, INEGI. (2017, septiembre 29), Estadísticas sobre las afectaciones de los sismos de septiembre de 2017 en las actividades económicas. Comunicado de prensa núm. 419/17.

Ishii, T (2016, marzo 16), Business Interruption Risk and Its Relationship With the Global Economy. Retrieved from Gen Re: http://www.genre.com/knowledge/blog/business-interruption-riskrelationship-with-the-global-economy-en.html

Kumar Jain, V y J Guin (2009), "Modeling Business Interruption Losses for Insurance Portfolios". 11th Americas Conference on Wind Engineering. Puerto Rico.

London Business Interruption Association. (n.d.), LBIA guide to business interruption insurance and claims. Inglaterra.

National Research Council, NRC. (1999), The impacts of natural disasters: a framework for loss estimation. Washington, D.C.: National Academy of Sciences Press.

NTC-DCEM. (2017), Normas Técnicas Complementarias para Diseño y Construcción de Estructuras de Mampostería. Ciudad de México: Gaceta Oficial de la Ciudad de México.

Ordaz, M, E Miranda, E Reinoso y L Pérez Rocha (2000), "Seismic loss estimation model for Mexico City". 12 WCEE 2000 : 12th World Conference on Earthquake Engineering. Auckland, New Zeland: New Zealand Society for Earthquake Engineering.

Ortiz, D y E Reinoso (2017), "Estimación de pérdidas consecuenciales debidas al daño estructural por sismo en edificaciones de mampostería confinada". Primer Congreso Panamericano de Ingeniería Estructural . Tarija: UPADI.

Pujol, S y M Rodríguez (2019), "Evaluación del comportamiento de muros no estructurales en edificios de la Ciudad de México en el terremoto del 19 de septiembre de 2017". Revista de Ingeniería Sísmica, 53-66. DOI: $10.18867 /$ RIS.101.529

Ramírez C M, et al. (2012), "Expected Earthquake Damage and Repair Costs in Reinforced Concrete Frame Buildings". Earthquake Engineering \& Structural Dynamics, 1455-1475. DOI: 10.1002/eqe.2216

RCDF, (2017). Reglamento de Constrcciones para el Distrito Federal. Ciudad de México: Gaceta Oficial de la Ciudad de México.

Red Nacional de Evaluadores, ReNE. (2018, febrero 11), Metodología para la evaluación de la seguridad estructural de edificios. México: CENAPRED. 
Rodríguez, M (2019), "Interpretación de los daños y colapsos en edificaciones observados en la Ciudad de México en el terremoto del 19 de septiembre de 2017". Revista de Ingeniería Sísmica, 1-18. DOI: $\underline{0.18867 / R I S .101 .528}$

Rodríguez, M y E Castrillón (1995), Manual de evaluación postsísmica de la seguridad estructural de edificaciones. Informe No. 569, 84. México: Instituto de Ingeniería, UNAM.

Rose, A y D Lim (2002). "Business interruption from natural hazards: conceptual and methodological issues in the case of the Northridge earthquake". Environmental Hazards, 4, 1-14. DOI: 10.1016/S14642867(02)00012-8

Rose, A (2017), "Benefit-Cost Analysis of Economic Resilience Actions". Oxford Research Encyclopedia of Natural Hazard. DOI: 10.1093/acrefore/9780199389407.013.69

Ruiz, S, R Jiménez, M Santos y M Orellana (2020), "Evaluación de la fragilidad de dos soluciones de rehabilitación de un edificio de planta baja débil dañado durante el sismo 19/S17". Revista de Ingeniería Sísmica, 1-25. DOI: 10.18867/RIS.102.513

Scholl, R (1979), Seismic Damage Assessment for High-rise Buildings: Annual Technical Report. San Francisco, California: URS / John A. Blume \& Associates Inc. DOI: $10.3133 /$ ofr81381

Tapia, E y S García (2019), "Comportamiento de estructuras de acero durante los sismos de septiembre de 2017". Revista de Ingeniería Sísmica, 36-52. DOI: 10.18867/RIS.101.499

Tierney, K (1997). "Business impacts of the Northridge earthquake". Journal of Contingencies and Crisis Management, 5:2, 87-97. http://udspace.udel.edu/handle/19716/645

Webb, G, K Tierney y J Dahlhamer (2002), "Predicting long-term business recovery from disaster: a comparison of the Loma Prieta earthquake and Hurricane Andrew". Environmental Hazards 4:2-3, 45-58. DOI: 10.1016/S1464-2867(03)00005-6 